\title{
A interpretação marginalista do consumo conspícuo: inconsistências e limitações da síntese neoclássica da Teoria da Classe Ociosa *
}

\author{
Alexandre Ottoni Teatini Salles *** \\ Rafael Barbieri Camatta ${ }^{* * *}$
}

\begin{abstract}
Resumo
A teoria do consumo conspícuo é um elemento da construção teórica Vebleniana elaborada originalmente em seu primeiro livro A Teoria da Classe Ociosa. O termo é entendido como o padrão de consumo (especialmente) da classe ociosa usado como símbolo de status, demonstração de prestígio individual e de distinção social. Assim sendo, apresenta um importante componente cultural em que as preferências são formadas endogenamente, sendo emulado pelas outras classes, tornando-se, portanto, um comportamento socializado. Em meados do século XX, esta ideia geral de que classes mais ricas procuram demonstrar riqueza através do consumo de bens de luxo foi absorvida pela microeconomia convencional. O objetivo deste artigo é examinar as características gerais do conceito Vebleniano e demonstrar as inconsistências e limitações de sua "neoclassização". Conclui-se que sua interpretação neoclássica implicou em determinadas abstrações que viesaram a proposta original do autor institucionalista.
\end{abstract}

Palavras-chave: Consumo conspícuo; Interpessoalidade das preferências; Veblen, Thorstein, 1857-1929.

\begin{abstract}
The marginalist interpretation of conspicuous consumption: inconsistencies and limitations of the neoclassical synthesis of the theory of the leisure class

The theory of conspicuous consumption is an element of the Veblenian theoretical construction originally elaborated in his first book The Theory of the Leisure Class. The term is understood as the level of consumption (especially) of the leisure class used as a status symbol, a demonstration of individual prestige and social distinction. Thus, it presents an important cultural component, in which preferences are formed endogenously, emulated by the other classes, and thus become a socialized behavior. By the middle of the twentieth century, this general idea that richer classes seek to demonstrate wealth through consumption of luxury goods has been absorbed by conventional microeconomics. The purpose of this article is to examine the general characteristics of the Veblenian concept and to demonstrate the inconsistencies and limitations of its "neoclassization". It is concluded that this neoclassical interpretation resulted in certain abstractions that justified the institutionalist author's original proposal.
\end{abstract}

Keywords: Conspicuous consumption; Intersubjective preferences; Veblen, Thorstein, 1857-1929.

JEL B15, B21, D11.

\section{Introdução}

Thorstein B. Veblen (1857-1929) é conhecido como o precursor de uma Escola de pensamento da ciência econômica que foi batizada por Hamilton (1918) de Economia

\footnotetext{
* Artigo recebido em 6 de julho de 2015 e aprovado em 3 de fevereiro de 2019.

${ }^{* *}$ Professor associado do Departamento de Economia e do Programa de Pós-Graduação em Economia da Universidade Federal do Espírito Santo (UFES), Vitória, ES, Brasil. E-mail: aotsalles@ gmail.com.

${ }^{* * *}$ Doutorando do Programa de Pós-Graduação em Economia da Universidade Federal do Espírito Santo, (UFES), Vitória, ES, Brasil. E-mail: rbcamatta@gmail.com.
} 
Institucional, e chamada por Boulding (1957) e Kapp (1968) de Institucionalismo Americano. Décadas mais tarde, devido ao surgimento de outra agenda de pesquisa também relacionada às instituições, a abordagem Vebleniana foi denominada Institucionalismo Original (ou Velho Institucionalismo) por Hodgson (1989), Langlois (1989), Mayhew (1989) e Rutherford (1989). As obras completas do autor envolvem a publicação de mais de cem artigos e de onze livros (Camic; Hodgson 2011) abarcando teoria e aplicação de seu método aos mais variados temas de sua realidade histórica. Sua principal contribuição para a ciência econômica foi a proposição de uma economia política evolucionária de inspiração darwiniana, com importante rigor sociológico e antropológico. Por conseguinte, recusou-se aceitar a hipótese de que a característica primordial do comportamento humano é determinada por racionalidade substantiva, hedonismo e imutabilidade.

A partir de um sistema de economia política antropológico-evolucionário (Cavalieri, 2009) o autor investigou temas da ciência econômica em claro contraste com a abordagem convencional de sua época. Isso inclui, por exemplo: a natureza epistemológica da Economia; a evolução histórica da sociedade humana enquanto desenvolvimento de suas instituições; a metodologia econômica; as características da atividade industrial, passando por discussões sobre estruturas de mercado, ciclos econômicos, sistema de preços e de crédito; a estrutura das classes sociais, envolvendo discussões sobre seus hábitos de vida, padrões de comportamento e de consumo; o papel das instituições na determinação da atividade econômica; além de temas relacionados a relações internacionais, nacionalismo, judaísmo, guerra, ensino superior e a condição da mulher na evolução histórica das sociedades.

Baseado em suas pesquisas acerca da natureza da vida sob o sistema pecuniário, Veblen estabeleceu as causalidades dos fenômenos econômicos e sociais dentro de uma perspectiva evolucionária. Ou seja, a atividade econômica é resultado de uma sequência cumulativa de eventos que se desdobram no tempo gerando consequências que são, simultaneamente, não antecipáveis (por isso, não calculáveis) e imprevisíveis. A isso, ele denominou (unfolding) sequence of cause and effect (1898a [2017], 1909). Assim, buscou compreender e analisar características do comportamento humano até então não incorporadas à análise econômica convencional, tais como: instintos, hábitos, instituições, costumes, códigos de conduta, valores humanos ligados a comportamentos idiossincráticos, e rivalidades sociais.

$\mathrm{Na}$ teoria institucionalista e evolucionária do autor, a sociedade é vista como um organismo complexo que evolui a partir das mudanças sequenciais e cumulativas ocorridas na estrutura institucional na qual se estabelece. Em outras palavras, a evolução social é um processo de seleção natural das instituições de forma que a vida do homem em sociedade assemelha-se (metaforicamente) à luta pela sobrevivência das espécies tal como proposto por Darwin. Veblen define instituições como hábitos de pensamento disseminados e arraigados na estrutura mental de uma sociedade que determinam o comportamento corriqueiro e o esquema de vida dos indivíduos (Veblen, 1898a [2017], 1898b e 1899 [1983]). Sendo assim, resultam de processos históricos passados, adaptados a circunstâncias sociais e culturais passadas, não estando por isso em pleno acordo com as exigências do presente. 
A teoria do consumo conspícuo é um aspecto da construção teórica Vebleniana elaborada originalmente em seu primeiro livro (sua obra mais conhecida), A Teoria da Classe Ociosa (1899) (TCO) ${ }^{1}$. Na TCO Veblen define consumo conspícuo como aquele que visa demonstrar, prima facie, que o agente possui um elevado nível de renda e faz uso disso por meio de ostentação consumista a fim de se diferenciar socialmente dos outros indivíduos. Através deste conceito, compreende-se que tal padrão de consumo era característico das classes abastadas almejando ostentar seu padrão de vida imódico. Ademais, Veblen (1899) assevera que este comportamento da classe ociosa influenciava a formação de preferências e o padrão de consumo das classes inferiores, de tal forma que estas procuravam emular o padrão de consumo daquelas. Desde então, esta interpretação tem impactado marcadamente a compreensão de scholars que estudam o consumo na sociedade moderna. Uma vez que o padrão de consumo típico da classe mais alta é emulado pelas classes mais baixas, o consumo ostentatório assumiu um caráter ubíquo. Assim, tornou-se um conceito amplamente utilizado por diferentes autores para interpretar o consumo com diferentes propósitos e sob diferentes pontos de vista (Edgell 1992; Trigg, 2001; Barreiro, 1998; Ayala, 2004; Gonzalez, 2008; Woodside, 2012; Figueras; Morero, 2013).

Esta ideia geral de que classes mais ricas procuram demonstrar sua riqueza através do consumo de bens de luxo foi absorvida pela microeconomia convencional em meados do século XX. Tendo isso em mente, o objetivo do artigo é apresentar as interpretações marginalistas do consumo conspícuo a partir do artigo seminal de Harvey Leibenstein (1950) até os estudos mais recentes, demonstrando que sua modelagem implicou em diversas abstrações que enviesam a proposta teórica institucionalista e evolucionária de Veblen. Por isso, propõe-se que houve uma interpretação marginalista da abordagem Vebleniana do consumo, ou seja, uma neoclassização do conceito, em oposição à sua conotação original (semelhante ao que foi feito com o pensamento de Keynes no âmbito da Síntese Neoclássica). O artigo demonstra que autores marginalistas (de forma explícita ou não) absorveram o conceito, mas não a metodologia e a ontologia que o fundamenta. Esta ampliação das fronteiras do pensamento convencional "abrindo sua agenda, fechando questões pendentes e uniformizando o discurso

(1) Na verdade, Veblen mencionou pela primeira vez em sua obra o termo "consumo conspícuo" no artigo The Economic Theory of Women's Dress publicado cinco anos antes da TCO. Apesar do termo em si aparecer pela primeira vez somente na última frase do texto, nele o autor deixa claro que o padrão imediato e óbvio de força pecuniária do agente é sua capacidade de gastar e consumir improdutivamente, colocando em evidência (exibindo) as mercadorias caras consumidas. Evidenciada por seu "sucesso visível", este nível de consumo é a base da premiação social e do respeito popular, estabelecendo assim uma diferenciação de classe social de seus donos. Nestes termos, tal discussão está muito próxima da que é feita na TCO. Contudo, é restrita ao debate acerca do vestuário feminino uma vez que as mulheres têm a (alegada) função de exibir a força pecuniária de suas vestimentas "em um grau peculiar". Não há, portanto, uma discussão mais geral e pormenorizada sobre o tema, como é de se esperar em função das limitações de um artigo. Apesar disso, este texto pode ser considerado o preâmbulo do tratamento teórico que o autor dá ao tema no livro anos mais tarde. 
cada vez mais formalizado" foi chamado metaforicamente por Possas (1997) de "cheia do mainstream".

$\mathrm{O}$ artigo possui quatro seções adicionais. Na seguinte, apresenta-se a teoria do consumo conspícuo tal como discutida por Veblen na TCO. A seção 2 examina as interpretações marginalistas do consumo conspícuo iniciando com o artigo seminal de Leibenstein (1950) e avança para autores mais recentes. Em seguida, procura-se demonstrar como o consumo conspícuo foi interpretado pela abordagem convencional, propondo que ocorreu uma neoclassização da TCO. Por fim, considerações finais concluem o artigo.

\section{0 consumo conspícuo segundo a interpretação Vebleniana}

De acordo com Mason (2002), Veblen desenvolve uma abordagem de natureza histórica-antropológica-sociológica acerca do consumo na TCO. Tal interpretação está ligada à sua teoria do processo de decisão que se assenta em uma construção ontológica do agente erguida sob os conceitos de instintos, hábitos e instituições (Salles; Camatta, 2017). Assim, uma análise Vebleniana do consumo propõe que o padrão de comportamento do consumidor está relacionado não apenas às escolhas dos indivíduos isoladamente, mas principalmente aos hábitos mentais desenvolvidos por eles, enraizados em sua cultura. Isso significa que o consumo apresenta um caráter inerentemente social e cultural. Significa também que o autor entende o consumo em uma perspectiva evolucionária uma vez que leva em consideração as características e as mudanças no comportamento dos indivíduos ao longo do tempo diante da interação destes com o ambiente social. Isso quer dizer que alterações estruturais no perfil das instituições e das relações econômicas e sociais são importantes para descrever as particularidades do fenômeno. Trata-se, portanto, de um conceito histórica e institucionalmente denso.

No livro de 1899, Veblen apresenta as condições históricas subjacentes ao surgimento da classe ociosa. Esta é considerada a classe social responsável por ocupações governamentais, bélicas, religiosas e esportivas, sendo por isso isenta de qualquer função industrial. Ao identificar as características idiossincráticas do comportamento desta classe afortunada financeiramente e privilegiada socialmente, Veblen elabora sua visão sobre o que chamou de

(2) Logo no início do artigo, Possas (1997, p. 14) define o que chamou de "método tipicamente neoclássico" da seguinte forma: "aquele que assume, necessariamente, a racionalidade substantiva (na expressão de Simon) maximizadora como norma de decisão dos agentes econômicos, e o equilíbrio como norma de atuação dos agentes ou, pelo menos, de operação dos mercados individualmente, em conjunto (equilíbrio geral) ou ainda no agregado". A partir daí, ele usa os termos mainstream, neoclássico, ortodoxo, e convencional com o sentido especificado acima. Contudo, anos mais tarde, surge uma discussão sobre a adequação do emprego destes termos indistintamente em função do aumento da complexidade matemática e econométrica (leia-se, da complicação formal) dos modelos recentes. Este debate foi além de uma mera questão de taxonomia conceitual. Nesta discussão sobre uma maior ou menor generalidade e temporalidade de aplicação destes conceitos, estão Hodgson (1999), Colander, Holt e Rosser (2004), Lawson (2006) e Dequech (2007). Este artigo lida com esta temática apenas secundariamente, por isso está fora de seus objetivos enveredar neste debate. Cumpre apenas deixar claro que adotamos não só a definição acima proposta por Possas (1997), como também a forma pela qual ele usou as expressões mainstream, neoclássico, ortodoxo, convencional, incluindo o termo marginalista não mencionado pelo autor. 
consumo conspícuo. Para o autor, o consumo não é somente motivado pela necessidade (no sentido de indispensável à subsistência), ou até mesmo pelo conforto que ele confere, mas também pelo apelo ostentatório intrínseco à sua aquisição. Isso significa que muito além das necessidades físicas, espirituais ${ }^{3}$, estéticas e intelectuais, o consumo para esta classe serve como forma de demonstração de honorabilidade e distinção, sendo um importante meio de materializar status social a seu possuidor.

Para o precursor da Economia Institucional, a mola propulsora do consumo é a emulação pecuniária, ou seja, a necessidade de cada indivíduo sobrepujar outros agentes na acumulação de bens. Neste caso, o indivíduo busca a demonstração (leia-se, ostentação) de sua riqueza para satisfazer seu instinto de competição pecuniária de tal forma que a posse da riqueza torna-se, por si só, honorífica. Em outras palavras, a propriedade de bens adquire valor principalmente como prova de superioridade daquele que a possui em relação aos que não dispõem de haveres materiais. No momento em que a atividade industrial se sobrepõe à atividade predatória (ou seja, às funções meramente pecuniárias e não produtivas), “a posse da riqueza se torna relativamente mais importante e mais eficaz como a base costumeira de estima e reputação" (Veblen, 1899 [1983], p. 17).

O apego aos bens materiais é de tal modo elevado que não é possível conquistar uma posição honrosa na sociedade moderna sem a propriedade deles, uma vez que esta torna-se a base convencional da estima social. Isso significa que a opulência, inicialmente valiosa como prova de aptidão industrial, torna-se um ato digno por si mesmo pois confere honra a seu possuidor. Por isso, Hamilton (1987) considera que a visão de Veblen sobre o consumo tem duas dimensões: uma cerimonial e outra instrumental. Ou seja, o consumo serve de símbolo de status social e, simultaneamente, como um instrumento para alcançar determinado fim, a ostentação.

Veblen não descarta a importância da utilidade como "o elemento mais patente" que motiva o consumo. Contudo, ele propõe que há uma motivação mais significativa do que esta ao afirmar que a emulação é a "prova honorífica de prepotência do dono" (1899 [1983], p. 16). Ou seja, conquanto a utilidade - proveniente da necessidade - seja um elemento que leva ao consumo, é a ostentação de riqueza que representa o comportamento típico do consumidor. O desenvolvimento das técnicas industriais e o consequente aumento em eficiência do sistema econômico acarretaram uma "luta ulterior pela riqueza" como a necessidade de melhoria no

(3) O termo "espiritual" é muito comum na TCO (como também em outras obras do autor) e, não raro, dá margem a dúvidas ao leitor não acostumado com seu linguajar filosófico. Certamente, ele não se referia às substâncias incorpóreas, seres angelicais e/ou às almas dos vivos e mortos. A palavra era de uso corrente dos cientistas sociais e da filosofia da época e tinha vários significados podendo por isso ser utilizada de diversas formas. No contexto em que Veblen a utiliza, pode-se mencionar os termos "razão", "substância na qual reside o pensamento", "consciência", ou "intelecto" como significados mais aproximados extraídos da interpretação de Descartes. 
modo de vida, principalmente pelo aumento dos "confortos físicos" que o consumo proporciona $^{4}$.

A mercadoria consumida para ostentação tem um "período de validade" curto pois desde que deixa de ser considerada novidade já não é capaz de promover comoção. Logo, os agentes são obrigados a continuar consumindo produtos diferenciados de modo a manter o objetivo ostentatório atribuído a este hábito. A moda é um dos resultados desta tendência. Ela se modifica em períodos curtos (por exemplo a cada estação, no caso do vestuário) orientando os consumidores a manterem-se sempre dentro destes padrões estabelecidos culturalmente pela classe ociosa.

Quando o nível de renda do agente atinge um patamar superior ao que é necessário à sua subsistência, a maior parte dos aumentos posteriores que ele obtiver será dedicada ao consumo conspícuo. Portanto, os ganhos de produtividade advindos de novas tecnologias e qualificação do trabalho tendem a aumentar os gastos conspícuos ao invés de reduzir sua quantidade de trabalho. Em outras palavras, o agente não diminui seu número de horas trabalhadas a fim de assim aumentar sua renda e, por conseguinte, seu gasto conspícuo emulatório.

O conceito de emulação pecuniária também engloba o de ócio conspícuo. $\mathrm{Na}$ abordagem Vebleniana, ócio significa simplesmente tempo gasto em qualquer atividade nãoprodutiva. $\mathrm{O}$ tempo despendido nestas atividades decorre, primeiramente, pelo indecoro do trabalho industrial (repetitivo). E, em segundo lugar, como prova da necessidade de cada indivíduo de superar o outro através de sua opulência pecuniária, que permite não tenha necessidade de empreender qualquer atividade ligada à produção.

O aprendizado formal de boas maneiras é um exemplo de ócio conspícuo uma vez que requer dispêndio de tempo e treinamento em atividades não produtivas. Como forma de ocupação digna do tempo ocioso, a boa educação não é somente um sinal de excelência, mas um traço da alma de seus detentores. Assim, o valor intrínseco das boas maneiras está no fato de que são prova de uma vida opulenta. Ou seja, ócio conspícuo demonstra a capacidade do indivíduo de se sustentar sem exercer qualquer tipo de trabalho produtivo, o que contribui para sua própria respeitabilidade.

Tanto o ócio quanto o consumo conspícuo servem para demonstração pecuniária de poder, obtendo eficácia semelhante. Assim, a opção entre a emulação via ócio ou consumo conspícuo depende da ocasião e do grupo para qual se deseja atingir. Contudo, de acordo com o autor institucionalista, a melhor maneira de se demonstrar honorabilidade é de fato o consumo conspícuo exatamente por conta de seu mecanismo emulativo. Veblen reconhece que em estágios primitivos da civilização em que as comunidades eram de menor porte, tanto o ócio quanto o consumo conspícuos eram formas eficientes de demonstração pecuniária. Contudo,

(4) Portanto, ao associar consumo apenas à utilidade, omitindo seu papel enquanto prova de respeitabilidade, nobreza e distinção, a Escola Marginalista comete um erro teórico e histórico. Esta discussão será feita na seção 3. 
com o avanço da urbanização e o crescimento demográfico, surge a crescente necessidade de demonstrar riqueza a um número cada vez maior de pessoas em localidades mais distantes. Por isso, o ócio torna-se pouco eficaz e a demonstração de riqueza se concentrou no consumo. Ócio exige que o observador tenha um conhecimento maior sob o observado, enquanto o consumo de luxo (mansões, jóias, carros) são imediatamente sinalizados aos observadores ${ }^{5}$.

Segundo Veblen, a regra do dispêndio honorífico influencia as escolhas dos indivíduos no que se refere à beleza, utilidade e obrigações. Neste ponto, o autor afirma que as regras do gosto possuem raízes "antiguíssimas" e antecedem o advento das instituições pecuniárias, como é o caso dos hábitos de pensamentos. No período onde as mercadorias ainda não eram elementos de emulação pecuniária pelos indivíduos, sua utilidade era o fator determinante para o consumo. De maneira involuntária, a beleza de um objeto está ligada a uma questão de facilidade de percepção, ou seja:

(...) a beleza de qualquer objeto percebido significa que a mente prontamente exerce a sua atividade perceptiva nas direções facultadas pelo objeto em questão. Mas as direções nas quais a atividade prontamente se desenvolve ou se exprime são as direções para as quais a mente se inclina mercê de um hábito longo e antigo (Veblen, 1899 [1983], p. 90).

A clássica comparação feita pelo autor entre duas colheres deixa clara a relação existente entre beleza e dispendiosidade. Uma colher feita à mão com requintes de estilo e forma não é mais útil, no sentido corriqueiro da palavra, do que uma colher do mesmo material feita à máquina em escala industrial. Porém, para o fim ostentatório, a colher feita à mão e mais cara (apesar de suas possíveis imperfeições) é mais efetiva do que a segunda, feita à máquina e mais barata. Assim, artigos produzidos à mão são mais exclusivos e, portanto, preferíveis àqueles produzidos em série no que se refere à dispendiosidade honorífica do tempo e esforço.

A utilidade de objetos, adornos e vestuários consumidos conspicuamente advém em maior grau à honra de sua posse do que à sua beleza intrínseca. Objetos belos e úteis são cobiçados como uma propriedade valiosa, e seu desfrute é uma maneira de demonstração pecuniária. Deste modo, qualquer objeto bastante valioso tem de se conformar não apenas aos requisitos da beleza como também devem ter um alto preço. Isso quer dizer que uma coisa dita bela e não dispendiosa, de fato não é bela. Por exemplo, um artigo pode ser rotulado de perfeitamente belo, contudo, após análise de seu valor estético, pode-se concluir que ele é apenas pecuniariamente honorífico.

Independente da classe social a que pertence o indivíduo, quando se trata do consumo conspícuo, o objeto deve apresentar beleza pecuniária como suplemento da beleza estética. $\mathrm{Ou}$ seja, um objeto não pode apenas ser belo fisicamente para ser atrativo e consumível. Ele precisa

(5) Este ponto suscita a discussão sobre o papel dos meios de comunicação na divulgação do "estilo de vida" de membros mais abastados da sociedade. Isto é tipicamente é mostrado em programas protagonizados por celebridades, em comerciais de televisão, revistas e outras mídias dedicadas à frivolidade, em colunas sociais, etc. 
também ter beleza pecuniária ${ }^{6}$ como forma de demonstração. Todavia, existem diferenças de gosto entre classes. Estas não se devem às características estéticas dos bens, mas sim aos hábitos de pensamento que determinam se o consumo de determinado bem é honorífico.

A determinação do padrão de gosto da maior parte da população passa pela escolha do que é belo, e do que não é. A compreensão deste aspecto é necessária para o entendimento das propostas até aqui expostas uma vez que envolve conjuntamente os conceitos de belo e honorífico. Nas palavras do próprio autor: "a regra do preço caro nos afeta de tal maneira ao ponto de fundir inextricavelmente (...) em nossa apreciação os sinais de preço caro com os belos traços do objeto e subordinar o efeito resultante ao rótulo de uma apreciação da sua simples beleza" (Veblen, 1899 [1983], p. 80).

A classe ociosa não utiliza apenas vestimentas e adornos como forma de demonstração de riqueza. O cachorro e o cavalo de corrida também são utilizados e apreciáveis para fins de ostentação. O cachorro pela relação de servidão estabelecida entre o animal e seu dono, principalmente por este constituir uma fonte de gastos supérfluos. Neste aspecto, Veblen faz uma analogia entre a servidão dos cães para com seus donos, e a servidão de um escravo a seu senhor. Como os animais de estimação são excluídos de qualquer vínculo industrial e a atenção despendida a eles é considerada inútil, pode-se então considerá-lo também como forma demonstração de ócio conspícuo. Por sua vez, o cavalo de corrida é um instrumento de jogo e não tem nenhuma função industrial, por isso, distancia-se do útil e aproxima-se do ócio. $\mathrm{O}$ apelo social intrínseco a estes animais representa um dispêndio honorífico, e por isso são considerados belos.

Neste ponto, pode-se destacar novamente a importância dos hábitos de pensamento para difusão e incorporação de certas atitudes presentes em cada época. Para Veblen, a ligação entre o valor estético e o valor pecuniário emulativo das mercadorias não está conscientemente manifesto na visão do consumidor. Por isso, a formação dos hábitos é indispensável para que as pessoas os aceitem. Ao fazer sua escolha em relação ao mais belo, uma pessoa não pondera se este objeto está carregado pecuniariamente uma vez que este é um pensamento que já está enraizado.

Pode-se inferir daí que os termos usuais para designar a beleza de determinado objeto são os mesmos utilizados para classificar objetos carregados pecuniariamente, porém sem deixar claro que este objeto está sendo julgado de uma forma honorífica. Assim, Veblen afirma que as exigências pecuniárias coincidem com as exigências de beleza na compreensão popular.

O hábito de observar os traços de dispêndio conspícuo na mercadoria e o apelo à sua utilidade emuladora influencia a escolha dos indivíduos. Isto conduz a uma mudança nos padrões pelos quais se mede a utilidade das mercadorias. Tal como sublinhado acima, qualquer artigo produzido precisa conter o elemento honorífico e o elemento da eficácia. Por isso,

(6) A beleza pecuniária é expressa através dos atrativos das mercadorias capazes de revelar demonstração pecuniária. Na visão de Veblen, isto se traduz por seu alto preço. 
Veblen afirma que nenhuma indústria produz mercadorias desprovidas do primeiro. Ele acrescenta que o indivíduo que fez da pobreza extrema uma virtude e insiste na eliminação de todos os elementos honoríficos ou de desperdício de consumo, não conseguiria suprir suas necessidades mais básicas no mercado moderno. Ademais, ele acharia quase impossível abandonar os hábitos "contemporâneos" de pensamentos de tal maneira que raramente poderia obter suprimento para subsistência sem que instintivamente incorporasse um produto supérfluo à sua lista de requisitos.

Com a produção em larga escala pela indústria e a diminuição dos custos unitários de produção, as mercadorias industriais passaram a representar uma situação de inferioridade, pois se tornaram mais baratas e acessíveis a mais pessoas. Logo, passaram a ser repudiadas pela classe mais alta da sociedade, tornando-se o que Veblen chama de "comum". Assim, seu consumo deixa de ser honorifico porque não serve aos propósitos de uma favorável comparação emuladora em relação aos outros consumidores.

Em última instância, o consumo conspícuo é uma forma de adequar o modo de vida dos indivíduos aos padrões estabelecidos pela sociedade. São estes padrões que determinam o que Veblen chama de "regra reguladora do consumo". O consumidor alheio a estas regras não está de acordo com os padrões de "decência, na qualidade, quantidade e grau dos bens consumidos" (Veblen, 1899 [1983], p. 55). Por sua vez, a formação das preferências de consumo está intimamente ligada aos demais interesses do indivíduo devido à estrutura intrincada entre os hábitos de pensamento econômicos e não econômicos. Desta forma, as regras de dispêndio (provenientes do interesse econômico) afetam os sensos de estética, honra, dever, etc.

Uma vez apresentados estes aspectos essenciais acerca da caracterização do consumo conspícuo, a seção seguinte examina como este conceito extraído da TCO influenciou autores marginalistas, e como estes o interpretaram dentro de seu próprio arcabouço teórico.

\section{A interpretação marginalista do consumo conspícuo}

A partir da década de 1950, o conceito de consumo conspícuo foi absorvido pela abordagem marginalista, incorporando-se na agenda de pesquisa desta Escola em discussões relativas a temas tais como funções de utilidade endógenas, externalidades de consumo, economia da informação, sinalização, teoria dos jogos, entre outras. Uma evidência da utilização mais ampliada deste termo foi apresentada por Weber (2011). Ele realizou uma pesquisa com o termo "conspicuous consumption" em artigos de revistas internacionais de grande prestígio em Economia no período entre 1894 e 2010, e constatou que este aparece 227 vezes. Contudo, ele observou que o nome "Veblen" é referenciado em apenas 85 destes artigos. Identificou também que os termos "Veblen Efect", "conspicuous consumption" e "prestigie goods" são utilizados como conceitos correlatos. Desta pesquisa, o autor conclui a interpretação marginalista do termo pode ser considerado de conhecimento universal na ciência econômica, 
Como é bem conhecido nos manuais de microeconomia, o consumidor neoclássico não se move no tempo histórico, mas no tempo lógico, uma vez que suas decisões devem ser passíveis de representação conceitual matemática. A fim de acomodar este tipo de comportamento, a literatura especializada apresenta uma série de argumentos como os bens substitutos, complementares, bens de Giffen, os diversos conceitos de elasticidade da demanda, etc. Estes demonstram que o comportamento do consumidor pode mudar intertemporalmente. $\mathrm{Na}$ prática, isso significa que a teoria propõe a hipótese de que há várias possibilidades de equilíbrio devido a mudanças de curto prazo nas preferências dos agentes. Em suma, a teoria neoclássica do consumidor propõe que agentes racionais buscam, de forma hedonista, maximizar sua função de produção (ou função utilidade no caso das famílias) por meio do cálculo marginalista de utilidade decrescente das mercadorias.

Nesta interpretação, o consumo conspícuo ocorre quando os agentes consomem os chamados bens de Veblen, ou seja, bens de elevado valor, cujo interesse está intimamente ligado a seu alto preço e sua estética, em detrimento de sua serventia. A este respeito, duas obras seminais são dignas de nota. A primeira é o livro Income, Saving and the Theory of Consumer Behavior de James Duesenberry publicado em 1949. Nele, o autor interpreta matematicamente a teoria do consumo Vebleniana sem, contudo, utilizar o conceito de utilidade marginal para tanto. Logo a seguir, em 1950, Harvey Leibenstein publica o artigo Bandwagon, Snob, and Veblen Effects in the Theory of Consumers Demand. Este foi pioneiro na interpretação da teoria do consumo conspícuo de Veblen a partir de uma abordagem marginalista.

A ausência de um debate teórico mais amplo sobre o consumo conspícuo tal como apresentado entre o surgimento da TCO (1899) e os trabalhos de Duesenberry (1949) e Leibenstein (1950) pode ser parcialmente explicado pelos rigores socioeconômicos decorrentes que caracterizou a primeira metade do século XX marcada por duas guerras mundiais e pela grande depressão. Este período conturbado de crises promoveu uma drástica redução do consumo de bens de luxo ao redor do mundo. $\mathrm{O}$ resgate das ideias relacionadas ao consumo conspícuo acontece justamente quando este torna-se mais evidente. Tal fenômeno coincide com o surgimento de instrumentos de publicidade e propaganda veiculados por diversos meios de comunicação - em especial pela televisão - que no pós-guerra já tinha se tornado acessível para grande parte das famílias americanas (Mason, 2002; Patsiouras; Fitchett, 2012). As grandes transformações ocorridas na dimensão do mercado de massa neste período foram determinantes para o restabelecimento dos debates em torno das preferências de consumo na ciência econômica (Mason, 2000).

Duesenberry (1949) foi o primeiro autor a utilizar a matemática para mensurar e prever a busca por status social e o consumo baseado nas decisões de outros agentes. O autor cita o trabalho de Veblen como uma influência em sua teoria sobre a interdependência de sistemas de preferências, porém não considera suas próprias pesquisas como uma continuação da teoria Vebleniana justamente pela utilização da modelagem matemática (que Duesenberry denomina 
A interpretação marginalista do consumo conspícuo: inconsistências e limitações da síntese neoclássica da ...

de Analytical Economics) ${ }^{7}$. Para ele, as preferências são formadas socialmente pela habituação dos agentes. Logo, seu livro não pode ser considerado como a primeira incursão marginalista sobre a teoria do consumo conspícuo, mas sim como uma primeira interpretação matemática sobre este tema ${ }^{8}$.

De fato, Leibenstein (1950) afirma que na época da publicação de seu artigo, a teoria do consumo conspícuo ainda não tinha sido absorvida pela abordagem marginalista ${ }^{9}$. Ele deu o primeiro passo nesta direção, introduzindo os conceitos de Snob Effect, Bandwagon Effect, e Veblen Effect. O consumo conspícuo é modelado a partir de curvas de demanda não aditivas uma vez que o autor postula que não seria possível somar as demandas individuais para obter uma curva de demanda agregada. Esta impossibilidade se deve ao fato de que, neste caso, o consumo de um agente influencia o dos demais. Afirma ainda que é possível abstrair este efeito (não aditividade da demanda) em diversos mercados, sem prejuízo da análise e da previsibilidade do comportamento do consumo dos bens normais. Todavia, este não é o caso dos bens que envolvem o consumo conspícuo, a moda, os bens "in style", e aqueles relacionados ao Veblen Effect, Snob Effect e ao Bandwagon Effect. Diante destes, é necessário relaxar a hipótese de aditividade e direcionar o estudo para as características interpessoais deste tipo de consumo.

Segundo Leibenstein (1950), a literatura sobre a interpessoalidade da utilidade, anterior à publicação de seu artigo, havia sido abordada de três diferentes formas: a primeira ele denomina sociológica, e equivale à interpretação Vebleniana tal como discutida anteriormente, apesar de não ter sido ele o primeiro autor a definir o conceito ${ }^{10}$. A segunda abordagem equivale

(7) Com relação à real influência de Veblen no trabalho de Duesenberry (1949), este artigo concorda com a interpretação de McCormick de que o livro de Duesenberry (1949) precisa da TCO para ser compreendido completamente. Em suas palavras (1983, p. 1128): "Veblen and Duesenberry were interested in different things, but it would seem that Income, Saving, and the Theory of Consumer Behavior requires The Theory of the Leisure Class to be complete".

(8) Para um histórico da influência do trabalho de Duesenberry (1949), ver Mason (2000).

(9) Todorova (2013) afirma que, além de Leibenstein (1950), Frank (1985) e Bagwell e Bernhein (1996) também foram proeminentes na discussão do consumo conspícuo a partir da teoria da utilidade marginal. Estes últimos serão discutidos a seguir. Segundo Todorova (2013, p. 1200): “... Leibenstein's (1950) famous formulation of 'Veblen, snob, and bandwagon effects' and Frank's (1985) discussion of 'positional goods', both based on a marginalist framework where utility functions give the structure of individuals' motivation. Other formulations include equilibrium signaling relation between price and utility derived through status (Bagwell and Bernheim1996)".

(10) De acordo com Leibenstein (1950), Veblen não foi o pioneiro na discussão sobre consumo conspícuo. Segundo ele, foi o economista escocês John Rae (1796-1872) quem propôs a primeira definição deste termo em um livro publicado em 1834. De fato, o trecho a seguir demonstra que Rae cunhou o termo com sentido correlato ao proposto por Veblen. Nas suas palavras (1834, p. XV): "There is a propensity among men to attain superiority over one another. This may be termed vanity, and is gratified by the evident possession of things which others have not the means of acquiring; and therefore by the possession of commodities of which the consumption is conspicuous, and which cost much labor, though not better qualified, or, though but little better qualified to supply real wants, than other commodities costing little labor." Para o autor, consumo conspícuo é definido como uma situação de superiority of men over one another. Ele afirma ainda que a produção destes bens necessita de uma quantidade superior de trabalho, o que pode ser análogo à discussão Vebleniana esboçada acima sobre a quantidade de trabalho necessário para a produção de uma colher feita à mão, pecuniariamente superior ao trabalho embutido na colher feita à máquina. Ademais, segundo o economista escocês, mercadorias conspícuas não podem ser analisadas a partir de sua utilidade, mas da capacidade destas em satisfazer as vaidades de competição dos agentes. Em suma, a abordagem de Veblen aproxima-se bastante do pensamento de Rae. 
à teoria do Welfare, cujo foco está na política pública voltada à regulação dos bens conspícuos e à melhor utilização dos recursos utilizados em sua produção. A terceira, denominada teoria pura, lida com a problemática da não aditividade das curvas de demanda.

Entre as hipóteses do modelo adotado por Leibenstein (1950) estão: (i) a adoção da metodologia estática, na qual a ordem dos fenômenos pode ser abstraída de tal forma que o recebimento da renda e o gasto podem ser considerados sincronizados; (ii) repetição dos padrões de renda destinada ao consumo entre períodos; (iii) toda a renda recebida no período é gasta (não existe poupança); e, (iv) a variação de preços e os desequilíbrios só podem ocorrer e serem resolvidos entre períodos.

Após explicitar os pressupostos do modelo, Leibenstein (1950) divide a demanda em dois tipos: funcional, a qual surge devido a características inerentes à commodity; e não funcional, que equivale a demandas impostas por motivações exteriores à própria mercadoria. Por sua vez, esta demanda não funcional é dividida em três partes de acordo com a motivação que a incita: efeitos externos da utilidade; motivos especulativos; e motivos irracionais. Os componentes da primeira categoria (expostos a seguir) são o foco de seu artigo. Quanto à segunda, o agente compra mercadorias na expectativa de que seu preço suba. Finalmente, nos motivos irracionais, estão representadas todas as demandas não classificadas na tipologia acima. Em relação às diferentes motivações da demanda, Leibenstein (1950, p. 197), afirma que: "It is not within the competence of the economist to investigate the psychology of this kind of behavior". Em outras palavras, o autor propõe que o comportamento psicológico que leva ao consumo conspícuo existe e, portanto, aquele que se interessa em estudar este tipo de consumo a partir de uma análise econômica deve considerar que este afeta a curva de demanda.

Os efeitos externos da utilidade dividem-se em três categorias: Bandwagon Effect, Snob Effect e Veblen Effect. O primeiro traduz situações onde a demanda individual de um produto conhecido num mercado definido depende tanto da qualidade deste bem quanto da demanda deste por outros agentes, considerando-se que há informação disponível suficiente em relação às demandas individuais. No caso do Snob Effect, a curva de demanda individual também depende da qualidade dos bens e da demanda de mercado, entretanto a relação com esta última é inversa. Neste, o comprador busca exclusividade, e quanto maior a demanda de mercado, menor o valor do bem. O caso extremo deste efeito é o bem no qual há somente um comprador.

No que tange ao Veblen Effect, novamente Leibenstein propõe que a utilidade da mercadoria não advém somente da sua qualidade intrínseca, mas também de seu preço (o que equivale a dizer que a utilidade é diretamente proporcional ao preço). Ao discutir este efeito, o autor assevera que a teoria do consumo conspícuo é de natureza sociológica, sutil e complexa. Contudo, ao formular sua análise, conclui que: “(...) we can, for our pourpose, quite legitmately abstract from the psychological and sociological elements and address our attention exclusively to the effect that conspicuous consumption has on the demand function" (Leibenstein, 1950, p. 202). 
A interpretação marginalista do consumo conspícuo: inconsistências e limitações da síntese neoclássica da ...

Com relação à diferença entre a interpretação de Leibenstein (1950) e Duesenberry (1949), ressalta-se que enquanto o primeiro acreditava que seria possível adaptar o tratamento microeconômico convencional da demanda ao consumo interpessoal, o segundo entendia que era necessária uma reformulação da modelagem sobre o consumo na teoria tradicional. Leibenstein afirma que a contribuição de seu contemporâneo foi extremamente importante, porém carecia de um maior detalhamento. Por último, pode-se notar que o livro de 1949 tem um caráter inerentemente macroeconômico, voltado para a determinação de políticas públicas, enquanto o trabalho de Leibenstein (1950) utiliza amplamente o aparato marginalista de caráter microeconômico (Mason, 2000, 2002).

Após do artigo de Leibenstein, o tema deixa de ser discutido na literatura internacional, ressurgindo no final dos anos 1980 com a publicação de uma série de artigos dedicados ao desenvolvimento de modelos, ainda mais formalizados, para a interpretação marginalista do conceito Vebleniano. Falando em termos bem mais amplos, Possas (1997, p. 13) afirma que o mainstream promoveu com grande intensidade o aumento da correnteza e a inundação das margens "na última década e meia, aproximadamente", ou seja, exatamente por volta deste período mencionado acima.

Por exemplo, Basmann et al. (1988) conceberam um modelo no qual os consumidores possuem dois componentes de utilidade que competem entre si: (i) a utilidade advinda dos ganhos de bem-estar; e (ii) uma utilidade secundária imanente dos ganhos "sociais" da posse de determinada mercadoria. Os autores baseiam seu estudo econométrico diretamente nos escritos de Veblen (particularmente da TCO) e não fizeram qualquer menção ao modelo convencional clássico elaborado por Leibenstein (1950), ao contrário da maioria dos autores neoclássicos examinados no presente artigo. Basmann et al interpretaram os dois tipos de consumo diretamente a partir dos conceitos marginalistas de utilidade, apesar de reconhecerem suas diferenças com a proposta original de Veblen. Neste estudo, os bens de consumo são divididos em 5 categorias, quais sejam: alimentos, vestuário, habitação, duráveis, e saúde, sendo utilizados dados dos EUA para o período 1948/79. O principal resultado do modelo (relacionados aos propósitos deste artigo) é que, nestes anos ocorreu um aumento significativo do consumo motivado pela utilidade secundária (ii), ou seja, aquela voltada para a emulação.

Anos mais tarde, Bagwell e Bernheim (1996) ${ }^{11}$ reinterpretaram as ideias propostas de Leibenstein desenvolvendo um modelo que retrata bens de mesma qualidade (bens idênticos) que são vendidos tanto como luxury brands (bens de luxo) quanto budget brands (bens comuns), porém, consideram que a venda dos primeiros gera uma renda mais elevada do que os outros. Os budget brands obedecem aos princípios clássicos da microeconomia convencional, e têm seu preço igualado ao custo marginal em uma estrutura de concorrência perfeita. Por outro lado, os luxury brands possuem preço superior a este custo (lucro econômico

(11) Segundo Weber (2011), a primeira versão deste artigo de Bagwell e Barheim (1996) intitulado "Veblen Effect in a Theory of Conspicuous Compsumption" foi apresentada em 1992 com outro título. A mudança se deve a inclusão de referência a Veblen em relação à conceituação do consumo conspícuo no texto mais recente. 
maior que zero). A diferença está justamente no preço pago entre os dois tipos, sendo que os consumidores que optam pelos luxury brands o fazem para demonstrar sua capacidade pecuniária.

Nesta perspectiva, o efeito Veblen ocorre quando os agentes aceitam pagar um preço maior por um substituto perfeito mais barato. O objetivo destes agentes é adquirir status social mediante o consumo conspícuo e a ostentação pecuniária. No modelo, a emulação ocorre quando eles procuram se diferenciar das classes inferiores, imitando o consumo das classes superiores. Bagwell e Bernheim (1996) afirmam que numa teoria de consumo conspícuo fiel aos princípios Veblenianos, a utilidade do bem deve ser definida a partir do status do consumo em detrimento dos preços. Todavia, na situação de equilíbrio, o status é sinalizado a partir dos preços.

Os motivos que estimulam a emulação ocorrem através de sinalização. Este conceito, comum na Nova Economia Institucional (teoria dos contratos) e na Nova Economia da Informação, equivale a uma situação onde uma parte (o agente) envia informações críveis sobre si à outra parte (o principal). No modelo do consumo conspícuo marginalista, o agente membro da classe superior sinaliza sua riqueza a partir do consumo de bens cujo preço seja proibitivo para as classes inferiores.

Em artigo aceito pelo Journal of Economic Psychology neste mesmo ano de 1996 (publicado em 1998), Chao e Schor dão continuidade às ideias propostas por Duesenberry (1949) e Leibenstein (1950) de que há um forte componente social nas demandas por consumo dos agentes. As autoras utilizam dados relativos à demanda de cosméticos norte-americana para ilustrar a correlação positiva entre o consumo destes bens (de alto preço) e a demonstração de status. A escolha deste tipo de bem se revela emblemática para ilustrar o consumo conspícuo nesta sociedade. Segundo os resultados do modelo, os agentes preferem (recorrentemente) consumir produtos substitutos quase perfeitos com preço superiores em aproximadamente 100 dólares como estratégia de emulação. É interessante ressaltar que apesar de propor uma interpretação marginalista do consumo conspícuo, as autoras fizeram referência em vários momentos à abordagem Vebleniana sobre o assunto através de citações diretas de trechos da TCO.

Aceito também em 1996, Corneo e Jeanne (1997a) publicaram o artigo "Snobs, bandwagon and the origin of social customs in consumer behavior" no Journal of Economic Behavior \& Organization. Numa alusão explícita a Leibenstein (1950), os autores utilizaram os efeitos bandwagon e snob para ilustrar como normas sociais são criadas por agentes e instituições ao longo do tempo. Apesar da discussão acerca dos diferentes tipos de consumo, o objetivo principal do paper foi apontar as situações em que as firmas decidem explorar os segmentos de mercados pautados por estas social norms. Contudo, neste artigo, há uma única referência à TCO em uma nota de rodapé, e o termo consumo conspícuo não foi sequer mencionado. 
Porém, neste mesmo ano, estes mesmos autores publicaram outro artigo cujo objetivo foi desenvolver um modelo em que consumidores sinalizam seu nível de renda através do consumo de bens conspícuos. Logo, ao contrário do anterior, neste o consumo conspícuo aparece já no título e Veblen é amplamente mencionado no texto. Os artigos apresentam dois modelos diferentes de sinalização, ambos baseados nos conceitos de Snob e Conformism Effects de Leibenstein. Em Corneo e Jeanne (1997b) os bens conspícuos são classificados como indivisíveis, ou seja, o consumo de um agente necessariamente exclui os demais. Esta inclusão é importante para as conclusões dos modelos que objetivam ponderar quais seriam as políticas públicas eficientes para taxação (e até proibição) de bens demonstrativos.

Para os autores, havia certo consenso de que a alocação de parte da renda dos agentes para emulação gera distorções no mercado como um todo, inclusive de bens normais. Isto se deve-se ao fato deles deixarem de consumir bens normais para consumir de acordo com os efeitos snob e follower. Desta forma, caberia ao governo reduzir os mercados de luxo através de taxação. Contudo, discordam desta concepção pois demonstram que a taxação dos bens eleva os preços e gera um aumento do consumo conspícuo. Consequentemente, isso provocaria uma diminuição ainda maior do bem-estar social. Por fim, outra contribuição importante deste artigo em relação ao 1997a refere-se à provisão privada de bens públicos. Os autores propõem que uma das formas usuais de demonstração de riqueza advém dos gastos com filantropia. Assim sendo, os agentes sinalizariam seu poder pecuniário em doações e eventos de caridade.

Amaldouss e Jain (2005) abordam o consumo conspícuo a partir de um modelo baseado em expectativas racionais. Isto significa que os agentes podem cometer erros na definição de sua cesta de consumo, porém, estatisticamente, geralmente acertam. Isto ocorre num ambiente onde existem consumidores snob (no sentido dado por Leibenstein) e followers (que são impelidos a consumir o mesmo tipo de bem de seus pares) ${ }^{12}$. Ambas as demandas são interdependentes e se enquadram na classificação de Motivos Externos à Utilidade de Leibenstein (1950). Os autores afirmam que o modelo apresentado se diferencia da literatura sobre o tema pois se baseia em externalidades e considera tanto as ações quanto as expectativas do consumo de bens snob e followers. Os modelos microeconômicos de externalidade traduzem situações econômicas nas quais a ação de um agente gera custos ou benefícios para outros, que não participaram da decisão. Sendo assim, concluem que para bens conspícuos, a demanda só possui inclinação positiva caso o mercado possua tanto consumidores snob quanto followers. Caso haja somente uma das categorias, a curva de demanda é sempre negativamente inclinada.

Uma das conclusões obtidas neste modelo contraria Bagwell e Bernheim (1996) no que tange ao lucro econômico obtido na venda de bens de luxo. Para Amaldouss e Jain (2005) o lucro diminui com o snob effect e aumenta com o follower effect. Este fato se deve ao comportamento do consumo snob, no qual quanto maior o consumo de determinado bem,

(12) Conceito este semelhante ao Bandwagon Effect de Leibenstein (1950). 
menor é o interesse no consumo conspícuo deste (externalidade negativa de consumo). A estrutura de mercado analisada é o monopólio.

Na verdade, Amaldouss e Jain (2004) já haviam desenvolvido um modelo formal baseado na mensuração de utilidade no qual buscavam compreender a influência do componente social na demanda e na formulação de preços. Da mesma forma, as influências sociais no consumo dividem os agentes em dois grupos: conformisms e snobs. Similarmente, este efeito social no consumo é modelado tendo como base as externalidades em detrimento de sinalização. O modelo tenta prever como o preço de equilíbrio e a rentabilidade das firmas são afetados pelo grau de conformismo ou necessidade de diferenciação dos consumidores.

A inclusão do consumo relativo em adição ao consumo absoluto, implica em conflito entre o bem-estar individual e social. Frank (2005) ilustra este fato através da metáfora da corrida armamentista. Nesta situação, os agentes investem no setor bélico de modo a competir com os demais, porém estes gastos retiram renda de outros setores essenciais, deslocando assim o consumo de seu ponto ótimo. O autor apresenta o conceito de positional goods para caracterizar os bens cuja demanda é motivada pelo consumo relativo. Afirma que modelos que incorporam tais bens podem abranger diversos tipos de externalidades advindas deste tipo de consumo. Entre estas, aponta-se: efeito dos aumentos de gastos entre agentes de renda inferior mediante aumento de gastos em segmentos de renda superior; relação entre a desigualdade de renda e preço de imóveis, falências (de pessoas físicas), taxa de divórcios; e horas trabalhadas.

Charoenrook e Thakor (2008) incorporam um elemento extremamente importante à teoria do consumo conspícuo marginalista, qual seja, o custo de exposição das mercadorias (cost of display). O modelo elaborado por eles trata da riqueza sinalizada pelo consumo de bens de alto preço. Para os autores, o consumo conspícuo relaciona-se com os bens de luxo, e seu estudo se justifica pelo forte aumento no consumo deste tipo na segunda metade do século XX. Segundo eles, a produção destes bens é acompanhada por investimento intensivo em publicidade com o objetivo de caracterizar as mercadorias como símbolo de status. Influenciados pela interpretação Vebleniana do consumo conspícuo, apontam que a demonstração de riqueza não acontece somente na compra dos bens, mas na exibição destes. Esta análise está em pleno de acordo com Leibenstein (1950) no que tange a concepção do Efeito Veblen como ato de consumir e exibir um bem cujo preço é maior que o custo marginal de produzi-lo.

Em última instância, Charoenrook e Thakor (2008) constroem um modelo cujas premissas são a racionalidade substantiva e a livre entrada de produtores no mercado. Tal modelo busca analisar a sinalização de riqueza a partir do consumo conspícuo, englobando a exibição dos bens consumidos. Os autores discordam da literatura de consumo conspícuo marginalista anterior em dois pontos principais: primeiro, divergem de modelos em que o consumo de bens conspícuos gera um aumento direto de utilidade individual. Para os autores, o aumento da utilidade advém do status obtido pelo agente que consome bens caros e não do consumo em si. Em segundo lugar, acreditam que a abordagem que pressupõe mercados 
monopolísticos para tratar bens da moda não é suficiente para explicar o consumo de bens conspícuos no mercado competitivo. De acordo com eles, o modelo desenvolvido captura a intuição Vebleniana de formação de preferência por bens caros ao englobar o status à análise num âmbito de mercado competitivo.

Quanto ao mecanismo de exposição, os autores definem as display units como sendo o espaço físico e as oportunidades sociais de exposição; e os display costs como os custos derivados da escassez de display units. Esta limitação está relacionada tanto à incapacidade de se exibir uma grande quantidade de bens de alto valor (por exemplo, só é possível que o agente dirija um carro de luxo por vez), quanto ao limite estético da exposição, na qual a extrapolação fere as normas do bom gosto (por exemplo, limite de exposição simultânea de jóias). Afirmam que há duas maneiras de sinalizar riqueza: o consumo de bens de alto preço, ou seja, preço maior que o custo marginal; e o consumo de uma grande quantidade de bens a preços iguais ao custo marginal. No momento da decisão de emulação, o agente calcula o trade-off entre o preço do bem e custo de exposição destes.

Arrow e Dasgupta (2009) corroboram a tese de que o consumo conspícuo sinaliza a posse de riqueza uma vez que esta não é observável. Este tipo de consumo pode ser representado por uma variável na função de felicidade (usado por eles como sinônimo de função utilidade) dos agentes. Pressupondo que os agentes agem racionalmente nos moldes da abordagem convencional, asseveram que o consumo conspícuo não necessariamente leva ao excesso de consumo no presente. Desta maneira, conseguem equilibrar o quanto de bens de luxo serão consumidos tanto no presente quanto no longo prazo. Portanto, o objetivo dos autores é compreender como acontece essa escolha intertemporal na estrutura das funções de felicidade. De forma simplificada, o modelo pressupõe que são produzidos somente dois bens, e que ambos possuem características demonstrativas no sentido conspícuo. Desta forma, atinge-se o equilíbrio de mercado no sentido de Pareto quando a utilidade marginal no consumo do bem 1 é igual a utilidade marginal do consumo do bem 2 .

À luz do que foi estudado acerca da concepção do próprio Veblen sobre o consumo, a menção aos conceitos elaborados por ele não significa uma "conversão" dos autores à abordagem institucionalista. De fato, Arrow e Dasgupta fazem uma adaptação à estrutura teórica marginalista no qual prevalece o equilíbrio intertemporal no consumo de bens de luxo, tomando como dado o caráter emulativo desta decisão. Este distanciamento em relação à proposta original Vebleniana pode ser observado na seguinte passagem: "So, although we shall use Veblen's terminology here, we do not necessarily invoke the reasoning he deployed to explain why relative consumption matters to people" (Arrow; Dasgupta, 2009, p. 3).

Dentre os autores marginalistas estudados, Arrow e Dasgupta (2009) foram os únicos que modelaram o ócio conspícuo. Eles trataram este conceito Vebleniano como um bem conspícuo que pode ser observado através de dados relativos ao consumo de viagens, hotéis, ingressos para eventos artísticos, etc. A modelagem do ócio conspícuo é um elemento distintivo na literatura convencional e indica que os autores se ocuparam em captar formalmente o debate 
acerca do consumo conspícuo em uma dimensão mais ampla do que seus antecessores. De fato, ao longo do artigo, o autor institucionalista é citado diversas vezes, inclusive na epígrafe do texto. Isso demonstra o reconhecimento por parte da abordagem ortodoxa da relevância do conceito de consumo conspícuo elaborado por Veblen. Demonstra também o vigor da "cheia do mainstream" uma vez que ela incorpora este tema dando-lhe o status de "objeto cientificamente sério" (Possas, 1997). No caso específico deste artigo, é digno de nota que o tema tenha chamado a atenção de um autor que recebeu o Nobel de Economia por suas contribuições pioneiras fundadas no core do pensamento neoclássico, tais como a teoria do equilíbrio geral e a teoria do crescimento endógeno, dentre outras.

Há ainda vários outros modelos da agenda de pesquisa marginalista baseados na utilidade que não podem ser abordados nesta seção em função da limitação de espaço. Dentre eles, pode-se mencionar: a relação entre utilidade, consumo, lazer, status social e externalidades negativas advinda da poluição (Howarth, 1996) ${ }^{13}$; a relação entre consumo relativo, nível ótimo de taxação e crescimento econômico (Fischer, 2000); a relação entre consumo conspícuo, desigualdade social e horas trabalhadas (Bowles, 2004); a relação entre consumo conspícuo e seleção sexual (Fraja, 2008); a maximização de utilidade ao considerarse o consumo conspícuo sob a forma de inveja e orgulho (Friedman; Ostrov, 2008); a influência do consumo conspícuo nas elasticidades das curvas de demanda (Heffetz, 2011); e, a relação entre consumo conspícuo, taxa de poupança e capital humano (Moav; Neeman, 2012).

A fim de sumariar os principais argumentos elaborados pelos autores discutidos mais pormenorizadamente nesta seção, o Quadro 1 apresenta uma síntese de suas contribuições essenciais.

Quadro 1

Principais conceitos da interpretação marginalista sobre o consumo conspícuo

\begin{tabular}{|c|c|}
\hline Conceitos/autores & Definições \\
\hline Snob Effect (Liebenstein, 1950) & $\begin{array}{l}\text { O comprador busca a exclusividade e quanto maior a } \\
\text { demanda de mercado menor o valor do bem. }\end{array}$ \\
\hline $\begin{array}{l}\text { Bandwagon Effect (Liebenstein, 1950) } \\
\text { Follower Effect (Amaldouss; Jain, 2005) }\end{array}$ & $\begin{array}{l}\text { A demanda individual de um produto conhecido, num } \\
\text { mercado definido, depende tanto da qualidade deste bem } \\
\text { quanto da demanda deste bem por outros agentes. }\end{array}$ \\
\hline Veblen Effect (Liebenstein, 1950) & $\begin{array}{l}\text { A utilidade da mercadoria não advém somente da qualidade } \\
\text { intrínseca da mercadoria, mas também do preço pago por } \\
\text { este (utilidade é diretamente proporcional ao preço). }\end{array}$ \\
\hline $\begin{array}{c}\text { Bens de Veblen, Bens in style, Bens de Luxo, } \\
\text { Prestige Goods, Luxury Brands, Status Goods, } \\
\text { Positional Goods, Conspicuous Goods } \\
\text { (vários autores) }\end{array}$ & $\begin{array}{c}\text { Bens voltados ao Consumo Conspícuo, Consumo Relativo } \\
\text { e Motivos Externos à Utilidade. }\end{array}$ \\
\hline Cost of Display (Charoenrook; Thakor, 2008) & $\begin{array}{c}\text { Custo para a exibição da mercadoria para fins } \\
\text { demonstrativos. }\end{array}$ \\
\hline
\end{tabular}

Fonte: Elaboração própria.

(13) O autor introduz o conceito incomum de "preferências altruísticas" em contraponto às "preferências egoístas" da microeconomia tradicional. 
A interpretação marginalista do consumo conspícuo: inconsistências e limitações da síntese neoclássica da ...

\section{A síntese neoclássica da TCO}

O objetivo da seção 1 foi apresentar os fundamentos teóricos essenciais da teoria do consumo conspícuo de Veblen tal como discutido na TCO. Por sua vez, a seção 2 intentou demonstrar como alguns destes alicerces foram emoldurados pela abordagem convencional. Analisando estas seções em sobreposição, pode-se concluir que atingiu-se outro objetivo deste artigo, qual seja, revelar o contraste entre a proposta original da teoria e seu enquadramento na estrutura teórica neoclássica. Destarte, a fim de concluir o objetivo geral deste artigo, esta seção examina com mais detalhes as consequências da disparidade entre a proposição original de Veblen e sua contextualização convencional. Em alusão a um movimento semelhante ocorrido com as ideias de Keynes, chamamos esta neoclassização do Institucionalismo Vebleniano de Síntese Neoclássica da TCO. A análise que se segue procura deixar clara a inadequação desta interpretação vis-à-vis sua origem institucionalista.

A este respeito, um primeiro ponto a ser levantado refere-se à construção teórica e metodológica de ambas Escolas. O desacordo com os princípios dos marginalistas neoclássicos ${ }^{14}$ está presente em toda obra de Veblen. Em seu artigo clássico "Por que a Economia não é uma ciência evolucionária? ", publicado um ano antes da TCO, ele classifica a teoria destes autores (não só dos marginalistas) como pré-evolucionária, deixando claro que a interpretação que advoga sobre o funcionamento do sistema econômico é antagônica. Um dos eixos fundamentais de sua crítica é de natureza ontológica. O trecho abaixo é uma passagem muito citada deste artigo em que o autor elucida sua discordância com o hedonismo proposto pela ortodoxia econômica. Ele descreve, de forma satírica, o padrão de comportamento característico do Homo Economicus (o homem racional e autointeressado) estabelecendo em seguida os contrastes com sua abordagem evolucionária e institucionalista. Assim, Veblen (1898a [2017], p. 45) argumenta que:

A concepção hedonista do homem é o de uma calculadora relâmpago de prazer e dor, que oscila como um glóbulo homogêneo de desejo por felicidade sob o impulso de estímulos que o deslocam, mas o deixam intacto. Ele não tem nem antecedente, nem precedente. Ele é um dado humano isolado, definitivo, em equilíbrio estável, exceto pelos golpes das forças atuantes que o desloca em uma direção ou outra. Autoequilibrado no espaço elementar, ele gira simetricamente em torno de seu próprio eixo espiritual até que o paralelogramo de forças cai sobre ele, quando então ele segue a linha resultante.

A abordagem neoclássica concebe o agente econômico como um ser hedonista que toma decisões a partir de uma concepção de tempo lógico e mecânico. Logo, suas escolhas são reversíveis e abertas, o que significa que ele pode substituí-las a qualquer momento sem prejuízo de seu padrão de otimalidade e equilíbrio. Neste artigo de 1898a [2017], Veblen confronta esta proposição com a abordagem evolucionária que defende. Assim, em contraposição, a ontologia proposta por ele dispõe que o comportamento dos agentes no tempo

(14) O termo "neoclássico" foi introduzido na Ciência Econômica pelo próprio Veblen em um artigo publicado em 1900, portanto, logo depois da TCO. 
histórico é idiossincrático e, portanto, muda qualitativamente. Isto é, evolui juntamente com as instituições. Essa evolução resulta de mudanças em seus hábitos de pensamento, que promovem reconstrução dos valores, dos pactos, dos compromissos e da forma de viver dos indivíduos e da sociedade, afetando assim o processo de causação dos fenômenos econômicos. A partir deste entendimento característico de uma economia evolucionária, pode-se concluir que os agentes tomam decisões (inclusive as de consumo) num ambiente marcado por uma sequência cumulativa de evolução das instituições, o que desabona a possibilidade de prevalência de situações de equilíbrio como um somatório de posições de equilíbrios alcançadas individualmente.

Este primeiro argumento estabelece uma clara incompatibilidade teórica entre marginalistas e o institucionalismo Vebleniano. Depreende-se daí que o conceito do consumo conspícuo possui determinações analíticas evolucionárias contrárias à interpretação meramente teleológica presente na concepção hedonista da natureza humana ${ }^{15}$.

O próprio Veblen expressou em vários artigos seu descontentamento com a falta de realismo da teoria Neoclássica. No trecho abaixo, Mason (2002, p. 89) mostra que o autor tinha clareza que este problema envolvia inclusive a abordagem desta Escola acerca do consumo. E que isso era incompatível com sua abordagem evolucionária. Na passagem a seguir pode-se inferir que, de certa forma, o primeiro a identificar e rejeitar a interpretação marginalista do consumo conspícuo foi o próprio precursor da Economia Institucional.

Veblen had never been happy with the neoclassical approach to consumer theory, and between 1898 and 1900 published a series of articles in the Quarterly Journal of Economics (1898; 1899a, b; 1900) attacking many of the assumptions and perceived lack of realism implicit in much neoclassical theory. It was not acceptable, in Veblen's view, for economists to declare that they could only concern themselves with outcomes and not with the underlying motives of consumption, and he pressed for greater interest to be shown in the intersubjectivity of consumer demand as a means to a better understanding of consumer behavior. Veblen was particularly concerned with the importance of interpersonal effects on consumer preference formation, and in his The Theory of the Leisure Class ([1899c] 1957: 22-34; 68-101) he explored the nature of pecuniary emulation and of conspicuous consumption in both sociological and economic terms. ... Only by adopting interdisciplinary approaches to economic analysis, Veblen believed, would any real progress be made in developing a consumer theory, which could properly describe real-world market behavior.

No final do século XIX, período de grande vigor do pensamento neoclássico, Veblen trilhou o caminho oposto daquele seguido pela esmagadora maioria dos pensadores

(15) Nas palavras de Veblen (1898a [2017], p. 49): “Os economistas aceitaram as preconcepções hedonistas sobre a natureza humana e a ação humana, e o conceito de interesse econômico que a psicologia hedonista oferece não fornece material para uma teoria sobre o desenvolvimento da natureza humana. Sob o hedonismo, o interesse econômico não é concebido em termos de ação. Portanto, ele não é facilmente apreendido ou estimado em termos de crescimento cumulativo dos hábitos de pensamento, e não provoca, mesmo que se prestasse a isso, o tratamento pelo método evolucionário." 
econômicos do seu país e do mundo. Ele enveredou pela interface entre a Economia, a Sociologia e a Antropologia, ainda muito incipiente à época. Na verdade, ele foi um pouco além disso, propondo estabelecer nesta interface uma abordagem evolucionária utilizando o método biológico de Darwin (Hodgson, 1992, 2003, 2004a, 2004b, 2005). Como visto acima, isso implicou no abandono do individualismo metodológico, e, portanto, na crítica ao Homo Economicus enquanto padrão de comportamento humano. Apesar de reconhecer que o comportamento do ser humano é dotado de um sentido teleológico, propôs que sua conduta é pautada também por decisões não teleológicas regidas por instintos, hábitos e instituições. Isso significa que, além de um componente racional, as ações humanas são guiadas pelo que está inconsciente ou fora do alcance de sua capacidade imediata de fazer cálculos, em contraposição ao paradigma de racionalidade substantiva maximizadora postulada pelo mainstream.

No que se refere ao consumo, esta crítica tem consequências adicionais. Segundo Veblen (1898a [2017]), o modelo de homem racional, maximizador e calculista que age apenas teleologicamente a partir de preferências dadas torna a Economia uma ciência não evolucionária e um mero modelo mental abstrato. Uma vez guiada por instintos, hábitos e instituições, as ações e preferências se modificam ao longo do tempo histórico devido à influência de mudanças na cultura e nas transformações econômicas e sociais. Esta perspectiva contrasta com o comportamento de consumidor convencionado pela abordagem ortodoxa tal como apresentado nos modelos estudados na seção anterior.

Conclui-se, portanto, que na interpretação institucionalista de Veblen, o entendimento acerca da motivação que leva ao consumo é completamente diferente daquele proposto pela abordagem dominante, uma vez que prevalecem outras determinações enraizadas culturalmente e lideradas pelo padrão estabelecido pela classe ociosa. Ou seja, indivíduos consomem como forma de ostentação mediante a exibição de bens adquiridos e de demonstração de honorabilidade, muito diferente da abordagem mainstream na qual a ação racional do consumidor é a maximização de uma função utilidade (sujeito a restrição orçamentária) conducente a uma situação de equilíbrio intertemporal estacionário. Como visto, os conceitos de consumo e ócio conspícuo, assim como a emulação pecuniária, demonstram que a utilidade (tal como interpretada convencionalmente) não tem necessariamente ligação com o nível de consumo ou com as preferências do consumidor. Veblen demonstrou na TCO que esse tipo de comportamento em relação ao consumo esteve presente ao longo das diversas etapas de desenvolvimento das relações humanas, mudando apenas de forma.

À luz da discussão feita na seção 2, conclui-se que os autores mencionados extraíram o conceito de consumo conspícuo da TCO, enquadraram-no em sua própria agenda, mas obtiveram resultados contrastantes e restritivos em comparação à proposta evolucionária de Veblen apresentada na seção 1. Esta apropriação ocorreu através da elaboração de modelos formais que introduziram motivos externos à utilidade das mercadorias (aquelas não relacionadas à utilidade intrínseca do bem, por exemplo, a demonstração de riqueza) como elementos fundamentais à motivação por consumir. Além disso, utilizaram tanto mecanismos de externalidades do consumo quanto de sinalização de renda para enquadrar o consumo 
conspícuo no aparato convencional. Ao "neoclassizar" a abordagem do autor através destes modelos e artifícios, obteve-se resultados incompatíveis com a análise evolucionária institucionalista. Em suma, o Veblenianismo neoclássico está em claro desacordo com a proposta evolucionária e intersubjetiva preconizada por Veblen com respeito aos determinantes do consumo.

Isso remete ao que Possas (1997) chamou de "aumento da correnteza" na medida em que a incorporação do tema atraiu o interesse de uma proporção crescente de acadêmicos. Ademais, a seção 2 também revela que ocorreu também o fenômeno que ele chamou de “inundação das margens". Isso porque os autores supracitados elaboraram um arrazoado de preceitos, tal como Bandwagon Effect, Snob Effect, Veblen Effect, Cost of Display, e sinalização da riqueza, que, simultaneamente, absorveram conceitos Veblenianos e trouxeram novos temas de pesquisa sobre o assunto no interior da agenda convencional.

Tal segmentação é inerente à teorização marginalista. Prova disso é a afirmação de Leibenstein (1950) de que o estudo sobre os fenômenos psicológicos e sociais que geram as preferências estão fora do escopo de análise do economista (leia-se, da análise marginalista). Ele adiciona ainda que, devido à complexidade dos fenômenos sociais que cercam o consumo conspícuo, este economista deve abstrair parte destes e se concentrar exclusivamente no efeito do consumo conspícuo sobre a curva de demanda.

Outra crítica que pode ser feita quanto ao afastamento da interpretação marginalista do consumo conspícuo em relação à proposta original é a pressuposição acerca da homogeneidade dos produtos. Para Veblen (1899), é de suma importância considerar que as mercadorias possuem características distintas, e que a evolução das instituições determina as mudanças nas preferências dos consumidores. Entretanto, a teoria marginalista abstrai os componentes culturais e institucionais de sua abordagem sobre o consumo conspícuo e adota como premissa a homogeneidade dos bens. Weber (2011, p. 19) expõe este distanciamento da seguinte forma: "In our equilibrium-based aggregations in the modern language of economics we have lost Veblen's 'starting-point' and his explanation of evolutionary change".

Esta abstração - explícita ou implicitamente - de componentes sociológicos, antropológicos e institucionais do consumo objetivou, portanto, adaptar o conceito à modelagem marginalista neoclássica. Este esvaziamento conceitual é característico do individualismo metodológico que fundamenta o comportamento do tomador de decisão concebido por esta Escola. Ao contrário, Veblen entende que todo o consumo é interpessoal ${ }^{16}$. Em sintonia com o pensamento institucionalista, Hamilton (1973) afirma que, se essa "soberania" do consumidor de fato existiu, ela foi erodida pelo trabalho sistemático da publicidade. Pois, segundo o autor "all goods not only are status symbols but also are instruments to achieve some end in view" (Hamilton, 1973, p. 203-204).

(16) Leibenstein (1950) até reconhece esta interpessoalidade mas relega este tipo de comportamento a uma pequena fração do consumo total (como uma demanda não-funcional). 
A interpretação marginalista do consumo conspícuo: inconsistências e limitações da síntese neoclássica da ...

Anne Mayhew (2002) leva adiante o argumento Vebleniano acerca da motivação do consumo ao afirmar que "todo o consumo é conspícuo", ou seja, possui um componente social e cultural. A autora expressa sua perplexidade pelo fato da ciência econômica tradicional ter abstraído seu componente social e antropológico em favor de seu enquadramento em modelos matemáticos como um fim em si mesmo. Em suas palavras (2002, p. 45): "It is not too difficult to see what would be sacrificed if the anthropological view of consumption were accepted; it is harder to understand how economists have suppressed the evidence in favor of this view". Ademais, Mayhew (2002, p. 54) exprime também sua divergência com relação às abstrações elaboradas por Leibenstein (1950) para descrever a teoria do consumo de Veblen. Conforme citação abaixo, a autora considera "difícil" entender as restrições de sua interpretação neoclássica da TCO e aponta (corretamente, a nosso ver) a razão para tanto, qual seja, a falta de leitura da obra.

It should be noted that Leibenstein also offered a very narrow interpretation of what Veblen said, by describing the 'Veblen effect' as the result of a larger quantity of demand at higher prices, a smaller quantity at lower prices, with the 'snob' and 'bandwagon' effects attributed to others. It is difficult to understand how this narrow interpretation of Veblen's argument can be reached if the whole of The Theory of the Leisure Class is read.

De fato, o objetivo de Leibenstein e de seus adeptos mais recentes tem sido a mera incorporação de conceitos adaptando-os a funções-objetivo estocásticas maximizáveis. Isso não requer a leitura atenta e criteriosa dos textos originais, e nem preservar a coerência com a proposta teórica ou metodológica do autor institucionalista. Trata-se de elaborar uma operação de redução com vistas à sua adaptação aos requisitos de cálculo de agentes que fazem escolhas ótimas intertemporais. Isso porque o princípio da otimização tem papel fundamental como expressão de racionalidade, tanto individual quanto social. Além disso, tal procedimento confere tratamento científico do tipo hard core da ciência econômica, considerado por isso, aquele que é adequado para conferir cientificidade à teoria.

Na esteira desta discussão sobre neoclassização do consumo conspícuo de Veblen, Todorova (2013, p. 1193) enfatiza o argumento de Mayhew quando afirma:

No consumption is outside a social context, and all goods and services have ceremonial attributes. In that context, Ann Mayhew's statement that 'all consumption is conspicuous' is correct, since consumption patterns involve ceremonial attributes that are means to invidious distinction.

Portanto, esta abstração dos componentes sociais da teoria do consumo de Veblen é mais uma crítica à neoclassização elaborada pela Síntese Neoclássica da TCO. Mason (2000) atribui isso ao esforço empenhado pelos economistas mainstream entre as décadas de $1920 \mathrm{e}$ 1940 em construir uma "ciência social exata" embasada exclusivamente em dados estatísticos (Mason, 2000). Esta "cruzada" utilizou amplamente a construção de modelos que não comportavam uma teoria do processo de decisão na qual fossem integrados instintos, hábitos e 
instituições. Ademais, pregava que tais componentes poderiam ser abstraídos da análise econômica sem prejuízo para o poder de explicação da teoria. Embora a partir de 1950 tenha havido diversas incursões da teoria marginalista acerca da interpessoalidade do consumo sob a forma de modelos matemáticos, estas ainda se valem de abstrações que prejudicam a compreensão do processo de tomada de decisões habitual e não teleológico do agente econômico, tal qual vislumbrado por Veblen.

Ainda com relação às limitações e inconsistências que surgem ao tratar o consumo conspícuo sem considerar a importância do componente social e cultural, Todorova (2013, p. 1999) aponta mais alguns aspectos importantes da proposta Vebleniana. Segundo ela, o debate institucionalista sobre consumo envolve rotinas e a formação de hábitos, portanto está necessariamente articulado com a estrutura social. Além disso, ele não deve ser conceituado independentemente da distribuição e da estrutura de classes da economia. Assim, em suas palavras:

The concept of conspicuous consumption has been so readily uprooted from analysis of capitalism through the method of stripping it from its routine nature. Describing conspicuous consumption as an exceptional behavior and as part of discretionary spending ofuscates its stabilizing place in the capitalist economy. Examining routines necessarily involves discussion of habit formation, which prompts the articulation of a specific social structure. On the other hand, conceptualizing of conspicuous consumption independently of distribution and the class structure of the economy is enabled by its definition as an exceptional behavior.

Até este momento, procurou-se demonstrar as inconsistências e limitações da interpretação marginalista do consumo conspícuo à luz da proposta original elaborada por Veblen na TCO. Como dito acima, uma das motivações desta pesquisa foi o reconhecimento de um movimento intelectual similar ocorrido na segunda metade dos anos 1930 no âmbito da então incipiente abordagem macroeconômica elaborada por Keynes após a publicação da Teoria Geral (TG). Precisamente, em abril de 1937, John Hicks publica na revista Econometrica seu famoso artigo Mr. Keynes and the Classics: A Suggested Interpretation. Nele, o autor elabora um modelo de equilíbrio geral Walrasiano (conhecido como modelo IS/LM) utilizando conceitos desenvolvidos por Keynes na TG, que também viesou a proposta original do autor.

O texto de Hicks (1937) provocou o mesmo efeito em termos da interpretação neoclássica das ideias de Keynes da TG que o paper de Leibenstein (1950) acarretou na neoclassização do consumo conspícuo de Veblen da TCO. Hicks propôs uma solução matemática (portanto lógica) a partir de um sistema de equações simultâneas para entender a complexidade da construção teórica de Keynes. Apesar de sacrificar a diversidade analítica de Keynes, ele uniformizou metodologicamente a teoria do autor através de uma (supostamente) necessária complicação formal, dando-lhe status científico considerado aceitável para muitos acadêmicos da época. A elegância e simetria dos conceitos, a clareza da demonstração lógicodedutiva, e seu rigor matemático captou a mente de elevado número de economistas daquela 
A interpretação marginalista do consumo conspícuo: inconsistências e limitações da síntese neoclássica da ...

geração. A este respeito, é representativa a frase de Robert Clower (um dos alunos de Hicks) mencionada por Weintraub afirmando que: "No living scholar has done more than John Hicks to shape contemporary modes of economic analysis" (Weintraub, 1978, p. 120).

Mais tarde, o modelo IS/LM tornou-se a base do método analítico de diversas pesquisas que tiveram o mesmo objetivo de Hicks, qual seja, enquadrar os conceitos Keynesianos dentro dos axiomas da abordagem neoclássica. Emerge então uma interpretação propondo que a teoria Keynesiana como um caso particular do modelo geral neoclássico. Seus principais expoentes são Hansen (1938), Modigliani (1944), Samuelson (1947), Patinkin (1965), Friedman (1970), Gordon (1974), Tobin (1980), só para mencionar os mais conhecidos. Assim, a partir dos anos 1960, surge uma nova Escola chamada de "Síntese Neoclássica", título que representa bem o tipo de entendimento que foi dado ao pensamento heterodoxo de Keynes. Esta abordagem reduziu a TG a uma economia estacionária de equilíbrio estacionário, atemporal, onde a moeda é neutra no curto e longo prazo, tudo isso em franca contradição com a proposta original de Keynes e da Revolução Keynesiana. Uma vez que a "Síntese" foi uma tentativa de adaptar as principais contribuições do autor inglês dentro do aparato analítico convencional, este movimento ficou conhecido também como a neoclassização da TG de Keynes.

Assim como a Síntese procurou inserir fundamentos da macroeconomia de Keynes nos cânones do mainstream, similarmente, elementos teóricos essenciais subjacentes à teoria do consumo conspícuo tem sido objeto de neoclassização desde o artigo seminal de Leibenstein (1950) até anos recentes. Por isso, propõe-se que este movimento intelectual seja chamado de Síntese Neoclássica da TCO.

A Síntese Neoclássica da TCO também gerou uma perspectiva reducionista sobre a natureza do comportamento humano tal como proposto pela interpretação evolucionária de Veblen. Poder-se-ia argumentar que trata-se apenas de um conceito inserido em uma obra particular, e que portanto, seria um exagero afirmar que a neoclassização deste "caso particular" seja de fato relevante e objeto de pesquisa. Tal argumento não se sustenta uma vez que se contra argumenta - como procurou-se fazer ao longo deste artigo - que a teoria do consumo de Veblen envolve a construção ontológica que fundamenta a abordagem evolucionária do autor. Como afirma Cavalieri (2009, p. 249): "Se Marx e os clássicos se debruçaram sobre a produção, e os neoclássicos foram os teóricos da esfera das trocas, Veblen pôs o consumo no front do seu pensar econômico." Portanto, sua teoria do consumo está no centro de uma série de debates sobre a conduta humana que o distingue teórica e epistemologicamente da teoria convencional. Logo, a neoclassização deste princípio afeta mais do que um conceito particular disposto em um livro.

Ainda na década de 1970, começou a surgir, parafraseando Possas em sentido inverso, uma "enxurrada" de críticas à Síntese Neoclássica da TG elaboradas por autores PósKeynesianos de diversas gerações (por exemplo Pasinetti, 1974; Chick 1977, 1983, 1992; Weintraub, 1978; Davidson, 1991, 1994; Vercelli, 1991; Carvalho, 1992; Kriesler; Nevile, 2001; Lavoie, 2006, só para mencionar os mais conhecidos, mas a lista é muito mais extensa). 
Esta mesma "cheia da heterodoxia", contudo, não ocorreu na literatura institucionalista até o momento, uma vez que críticas à neoclassização da TCO por parte de autores institucionalistas têm sido escassas e acanhadas ${ }^{17}$. Além das que foram apresentadas nesta seção, identificou-se que existem outras encontradas na literatura Pós-Keynesiana que podem ser evocadas por autores institucionalistas. Aquelas elaboradas pelos scholars mencionados acima, concentramse no núcleo do pensamento macroeconômico de Keynes. Estas não serão evocadas aqui. Não obstante, a desaprovação da Síntese proposta por Minsky pode sim ser invocada como mais uma crítica institucionalista à neoclassização da TCO.

Segundo ele, a utilização do "método tipicamente neoclássico" é mais ilusório do que proveitoso para a interpretação do mundo real. Isso porque o mainstream que emerge com bastante vigor no pós-guerra se especializou em elaborar elegantes provas formais da validade de seus axiomas ainda que sob pressupostos altamente restritivos a respeito de sua relevância analítica. Este tipo de objeção é a mesma de um autor institucionalista frente à neoclassização da TCO. Ou seja, a mera assimilação de conceitos e a obtenção de elegantes provas formais sob a alegação de produção de avanços científicos gera resultados altamente restritivos, de tal forma que a relevância da teoria é questionada. Um pesquisador que conhece a estrutura causal na qual Veblen assentou sua teoria, apontaria esta mesma dicotomia entre relevância e elegância expressa por Minsky (1986, p. 5). Em suas palavras:

The existing standard body of economic theory - the so-called neoclassical synthesis, which takes on both a monetarist and an establishment Keynesian garb - may be an elegant logical structure, but it fails to explain how a financial crisis can emerge out of the normal functioning of the economy and why the economy of one period may be susceptible to crisis while that of another is not.

A discussão feita acima nos leva a salientar que o objetivo deste artigo não é demonizar a matemática e a econometria como métodos de investigação aplicáveis à ciência econômica. Isso seria, na verdade, enveredar para um outro extremo tão limitador e simplificador quanto o que se está criticando. Economistas heterodoxos usam a matemática e a econometria como instrumentos para obtenção e avaliação de resultados. Contudo, o fazem a partir de princípios teóricos constituídos sob bases epistemológicas próprias, distintas do mainstream. Um dos exemplos mais conhecidos a este respeito é a obra de Michal Kalecki. Sua trajetória intelectual demonstra claramente como um pesquisador não convencional se utiliza de modelos matemáticos para esquadrinhar questões complexas da ciência econômica sem utilizar o nível de abstração e os princípios prognosticados pela ortodoxia. Trabalhando como um tapeceiro, foi um dos primeiros autores não neoclássicos a elaborar modelos matemáticos e utilizar dados estatísticos para discutir fenômenos importantes como ciclos econômicos, pleno emprego, distribuição de renda, estruturas de mercado, desenvolvimento econômico, etc. Kalecki é dos

(17) Em artigo publicado no Journal of Economic Issues, Ackerman (1997) dedica uma seção para discutir o trabalho de Duesenberry, Leibenstein e autores que trataram teoricamente do componente social do consumo, utilizando para isso trabalhos publicados até 1996. Além desta limitação, o paper está voltado para uma discussão de HPE e não aborda as modelagens acerca do consumo conspícuo como uma tentativa de neoclassização da teoria de Veblen. 
autores heterodoxos mais influentes da do século XX. Foi ele mesmo influenciado por pensadores tão diversos quanto Karl Marx, John M. Keynes, Joan Robinson, Knut Wicksell, Rosa Luxemburgo e Joseph Schumpeter (Toporowski, 2013). Não obstante, construiu uma abordagem teórica própria que inspira as pesquisas de autores heterodoxos até hoje. A este respeito, o estudo de sua principal obra, publicada em 1954, revela de forma precisa sua interpretação acerca da natureza da atividade econômica. Neste livro, utilizou amplamente a matemática como instrumento de análise. Não obstante, já no título (Teoria da Dinâmica Econômica) ele revela a proposta Kaleckiana de tratar a economia como uma ciência não convencional.

Desde então, inúmeros autores heterodoxos (inspirados por Kalecki ou não) têm utilizado a matemática e a econometria como instrumento, não como princípio para construção teórica, obtendo com isso resultados auspiciosos em suas pesquisas (vide por exemplo, Hodgson; Knudsen, 2004, bem como Possas, 1984; Busato; Possas, 2016, só para mencionar dois autores citados neste artigo, mas a lista é bastante extensa e inclui autores Pós Keynesianos brasileiros e estrangeiros). À luz deste debate, reitera-se que o problema identificado neste artigo é a mera absorção de conceitos envelopados em modelos que procuram solução ótima (no sentido paretiano) pode até ser resultado de pesquisa científica do tipo hard science mas, ao contrário, acabam restringindo o vigor original da teoria institucional de Veblen.

Esta discussão acaba trazendo à tona o antigo (e interminável) debate sobre realismo na ciência econômica. Autores heterodoxos consideram que o excesso de abstração ("agentes representativos", "concorrência perfeita", "equilíbrio competitivo", "maximização intertemporal", "estacionariedade", "utilidade não-aditiva", etc.) que os modelos convencionais estabelecem, não têm nenhuma (ou muito pouca) aderência com a natureza do comportamento dos agentes no "mundo real". Logo, são irrealistas. Estes acadêmicos defendem que tal nível de abstração gera uma (também excessiva) complicação formal dos modelos e sacrifica o entendimento da complexidade do objeto "real".

Por outro lado, autores ortodoxos não têm dúvida de que é este tipo de tratamento que determina o caráter científico da ciência econômica, e, exatamente por este motivo, é necessário mais - e não menos - formalização. É o que se depreende de Lucas (1981) quando ele afirma que uma teoria é um conjunto explícito de instruções para construir um sistema que deve ser análogo ao da mecânica. Logo, a Economia não requer um conjunto de assertivas sobre o comportamento de agentes atravessados por imperfeições cognitivas que podem gerar decisões sub-ótimas, nem tampouco demanda aderência ao que se chama de "mundo real". Está fora de os objetivos deste artigo tratar em detalhes sobre este assunto. $\mathrm{O}$ que se procurou demonstrar é que a teoria da economia política antropológico-evolucionária de Veblen propõe que o entendimento da atividade econômica depende de relações de causa e efeito em sequência cumulativa. Por conseguinte, é incompatível com a analogia mecânica da abordagem convencional. 


\section{Considerações finais}

Conforme preconizado por Veblen na TCO, o comportamento dos indivíduos que compõem a classe ociosa transformou-se ao longo da História, porém, seus hábitos de vida e de pensamento se disseminaram, sendo o consumo conspícuo o principal deles. Este continua a permear a economia nas mais diversas formas: carros, imóveis, jóias, vestuário, celebrações, etc. Este é um ponto de grande interesse tanto para a ciência econômica quanto para áreas afins como o marketing e a administração.

Foi discutida também a interpretação marginalista do consumo conspícuo. De maneira geral, a teoria do consumo marginalista é caracterizada por modelos de maximização de utilidade a partir de preferências exógenas, enquanto a teoria de consumo do autor institucionalista equivale a uma análise evolucionária onde as preferências são formadas (de maneira endógena), de forma intersubjetiva dentro de um contexto de mudança social. Sendo assim, elas evoluem (mudam) com a sociedade. Na esteira deste debate, foi demonstrado que a partir dos anos 1950, a teoria do consumo conspícuo de Veblen foi incorporada à abordagem microeconômica marginalista gerando resultados contrastantes com sua proposta original.

O estudo apresentado neste artigo buscou evidenciar que a abordagem marginalista se afastou em alguns pontos chaves, principalmente em relação à abstração de componentes institucionais, sociológicos e psicológicos. Desta maneira, a análise acima demonstrou que, assim como na neoclassização da teoria Keynesiana, a Síntese Neoclássica Vebleniana da TCO foi mais enganadora do que útil para a interpretação do mundo real no que se refere à discussão sobre o consumo conspícuo. Representou, outrossim, um retrocesso, pois considerar que os determinantes do consumo podem ser captados exclusivamente a partir de modelos baseados na teoria da utilidade marginal, configura uma volta à epistemologia hedonista. E este é exatamente o motivo pelo qual Veblen (1898a [2017]) considerou a economia como uma ciência não evolucionária.

\section{Referências bibliográficas}

ACKERMAN, F. Consumed in theory: alternative perspectives on the economics of consumption. Journal of Economic Issues, v. 31, n. 3, p. 651-660, 1997.

ALMEIDA, F. Thorstein Veblen and Albert Bandura: A modern psychological reading of the conspicuous consumer. Journal of Economic Issues, v. XI.VIII, n. 1, p. 109-122, 2014,

AMALDOUSS, W.; JAIN S. Pricing of conspicuous goods: a competitive analysis of social effects. Journal of Marketing Research, v. 42, n. 1, p. 30-42, 2004.

AMALDOUSS, W.; JAIN S. Conspicuous consumption and sophisticated thinking. Management Science, v. 51, n. 10, p. 1449-1466, 2005.

ARESTIS, P.; SAWYER M. Path dependency and demand-supply interactions in macroeconomic analysis. In: ARESTIS, P.; SAWYER, M. Path dependency and macroeconomics. Hampshire: Palgrave Macmillan, 2009. 
A interpretação marginalista do consumo conspícuo: inconsistências e limitações da síntese neoclássica da ...

ARROW, K. J.; DASGUPTA P. S. Conspicuous consumption, inconspicuous leisure. The Economic Journal, v. 119, n. 541, p. 497-516, 2009.

AYALA, M. C. L. de. El análisis sociológico del consumo: uma revisión histórica de susdesarrollos teóricos. Sociológica, n. 5, p. 161-188, 2004.

BAGWELL, L. S.; BERNHEIM B. D. Veblen effects in a theory of conspicuous consumption. The American Economic Review, v. 86, n. 3, p. 349-373, 1996.

BARREIRO, A. M. La moda em las sociedades avanzadas. Papers, n. 54, p. 129-137, 1998.

BASMANN, R. L.; MOLINA D. J.; SLOTTJE, D. J. A note on measuring veblen's theory of conspicuous consumption. The Review of Economics and Statistics, v. 70, n. 3, p. 531-535, 1988.

BERNHEIM, B. D. A theory of conformity. Journal of Political Economy, v. 102, n. 5, p. 841877, 1994.

BOULDING, K. E. A new look at institutionalism. The American Economic Review, v. 47, n. 2, Papers and Proceedings of the Sixty-eighth Annual Meeting of the American Economic Association, May, 1957, p. 1-12.

BOWLES, S.; PARK, Y. Emulation, inequality, and work hours: was Thorsten Veblen right? University of Massachusetts Economics Department, 2004. (Working Paper Series). Disponível em: http://scholarworks.umass.edu/econ_workingpaper/62.

BUSATO, M. I.; POSSAS, M. Restrição externa e crescimento simulando um modelo multissetorial aberto. Economia e Sociedade, Campinas, v. 25, n. 2, ago. p. 279-313, 2016.

CAMIC, C.; HODGSONG, M. Essential writings of Thorstein Veblen. London and New York: Routledge, 2011.

CARDIM DE CARVALHO, F. Mr Keynes and the Post Keynesians: principles of macroeconomics for a monetary production economy. Aldershot: Edward Elgar, 1992.

CAVALIERI, M. A. R. O surgimento do institucionalismo norte-americano de Thorstein Veblen: economia política, tempo e lugar. Economia e Sociedade, Campinas, v. 22, n. 1 (47), p. 43-76, 2013.

CAVALIERI, M. A. R. O surgimento do institucionalismo norte-americano: um ensaio sobre o pensamento e o tempo de ThorsteinVeblen. Tese (Doutorado)-UFMG, Belo Horizonte, 2009.

CHAO, A.; SCHOR, J. B. Empirical tests of status consumption: evidence from women's cosmetics. Journal of Economic Psychology, p. 107-131, 1998.

CHAROENRROK, A.; THAKOR, A. A theory of conspicuous consumption. OLIN Business School, Washington University, 2008. (Working Papers).

CHICK, V. The theory of monetary policy. $2^{\text {nd }}$ ed. Oxford: Basil Blackwell, 1977. 
CHICK, V. Macroeconomics after Keynes. Oxford: Philip Allan, 1983.

CHICK, V. Financial counterparts of saving and investment and inconsistency in some simple macro models. In: ARESTIS, P.; DOW, S. (Ed.). On money, method and Keynes: selected essays Victoria Chick. London: Macmillan, 1992.

COLANDER, D.; HOLT, R.; ROSSER JR., J. B. The changing face of mainstream economics. Review of Political Economy, v. 16, n. 4, p. 485-499, 2004.

CORNEO, G. JEANNE, O. Snobs, bandwagons, and the origin of social customs in consumer behavior. Journal of Economic Behavior \& Organization, v. 32, p. 333-347, 1997.

CORNEO, G.; JEANNE, O. Conspicuous consumption, snobbism and conformism. Journal of Public Economics, v. 66, p. 55-71, 1997.

DAVIDSON, P. Controversies in post Keynesian economics. Aldershot: Edward Elgar, 1991.

DAVIDSON, P. Post Keynesian macroeconomic theory: a foundation for sucessful economic policies for the twenty-first century. Cheltenham: Edward Elgar, 1994.

DEQUECH, D. The demarcation between the "old" and the "new" institutional economics: recent complications. Journal of Economic Issues, v. XXXVI, n. 2 Jun. p. 565-572, 2002.

DEQUECH, D. Neoclassical, mainstream, orthodox, and heterodox economics. Journal of Post Keynesian Economics, v. 30, n. 2, p. 279-302, Winter 2007-8.

DUESENBERRY, J. S. [1949]. Income, saving and the theory of consumer behavior. Cambridge: Harvard University Press, 1952.

EDGELL, S. Veblen and post-Veblen studies of conspicuous consumption: social stratification and fashion. International Review of Sociology, v. 3, n. 3, 1992.

FIGUERAS, A. J.; MORERO, H. A. La teoria del consumo y de los ciclos em ThorsteinVeblen. Revista de Economía Institucional, v. 15, n. 28, p. 159-182, primer semestre 2013.

FISCHER, W. H.; HOF, F. X. Relative consumption, economic growth, and taxation: a generalization. Journal of Economics, v. 72, n. 3, p. 241-262, 2000.

FRAJA, G. D. The origin of utility: sexual selection and conspicuous consumption. Journal of Economic Behavior and Organization, v. 72, n. 1, p. 51-69, 2008.

FRANK, R. H. Choosing the right pond: human behavior and the quest for status. New York: Oxford University Press, 1985.

FRANK, R. H. Positional externalities cause large and preventable welfare losses. American Economic Review, v. 95, n. 2, p. 137-141, 2005.

FRIEDMAN, D.; OSTROV D. N. Conspicuous consumption dynamics. Games and Economic Behavior, v. 64, n. 1, p. 121-145, 2008. 
A interpretação marginalista do consumo conspícuo: inconsistências e limitações da síntese neoclássica da ...

FRIEDMAN, M. A Theoretical framework for monetary analysis. Journal of Political Economy, v. 78, n. 2, p. 193-238, Mar./Apr. 1970.

GONZALEZ, A. M. A contribuição de Thorstein Veblen para a Teoria da Moda. IARA Revista de Moda, Cultura e Arte, v. 1, n. 1, p. 22-67, 2008.

GORDON, R. A. Friedman's monetary framework: a debate with his critics. Chicago: University of Chicago Press, 1974.

HAMILTON D. What has evolutionary economics to contribute to consumption theory? Journal of Economic Issues, v. VII, n. 2, p. 197-207, 1973.

HAMILTON, D. Institutional economics and consumption. Journal of Economic Issues, v. XXI, n. 4, p. 1531-154, Dec. 1987.

HANSEN, A. Full recovery or stagnation? New York: McGraw Hill Book Company, 1938.

HICKS, J. Mr Keynes and the classics: a suggested interpretation. Econometrica, v. 5, n. 2, p. 147-159, Apr. 1937.

HEFFETZ, O. A test of conspicuous consumption: visibility and income elasticities. The Review of Economics and Statistics, v. XCIII, n. 4, p. 1101-1117, 2011.

HODGSON, G. M. False antagonisms and doomed reconciliations. In: HODGSON, G. M. Evolution and institutions: on evolutionary economics and the evolution of economics. Cheltenham, UK: Edward Elgar, 1999, p. 23-45.

HODGSON, G. M. Economics and institutions: a manifesto for a modern institutional economics. London: Cambridge and University of Pennsylvania Press, 1988.

HODGSON, G. M. Institutional economic theory: the old versus the new. Review of Political Economy, v. 1, n. 3, p. 249-269, Jul. 1989.

HODGSON, G. M. Thorstein Veblen and post Darwinian economics. Cambridge Journal of Economics, v. 16, p. 285-301, 1992.

HODGSON, G. M. The approach of institutional economics. Journal of Economic Literature, v. XXXVI, p. 166-192, 1998.

HODGSON, G. M. What is the essence of institutional economics? Journal of Economic Issues, v. XXXIV, n. 2, p. 317-329, Jun. 2000.

HODGSON, G. M. Darwinism and institutional economics. Journal of Economic Issues, v. XXXVII, n. 1, p. 85-97, Mar. 2003.

HODGSON, G. M. The Evolution of institutional economics Agency, structure and Darwinism in American institutionalism. London and New York: Routledge, 2004a.

HODGSON, G. M. Veblen and Darwinism. International Review of Sociology, v. 14, n. 3, p. 343-361, 2004b. 
HODGSON, G. M. The complex evolution of a simple traffic convention: the functions and implications of habit. Journal of Economic Behavior \& Organization, v. 54, p. 19-47, 2004.

HODGSON, G. M. Generalizing Darwinism to social evolution: some early attempts. Journal of Economic Issues, v. XXXIX, n. 4, p. 899-914, Dec. 2005,

HOWARTH, R. B. Status effects and environmental externalities. Ecological Economics, v. 16, n.1, p. 25-34, 1996.

KAPP, W. K. In Defense of institutional economics. The Swedish Journal of Economics, v. 70, n. 1, p. 1-18, Mar. 1968.

KALECKI, M. [1954]. Teoria da dinâmica econômica. São Paulo: Nova Cultural, 1977.

KEYNES, J. M. [1936]. A teoria geral do emprego, do juro e da moeda. São Paulo: Nova Cultural, 1996.

KRIESLER, P.; NEVILE, J. IS-LM and macroeconomics after Keynes. In: ARESTIS, P.; DESAI, M.; DOW, S. (Ed.). Money, macroeconomics and Keynes: essays in honor of Victoria Chick. 2001. v. 1.

LANGLOIS, R. N. What was wrong with the old institutional economics (and what is still wrong with the new)? Review of Political Economy, v. 1, n. 3, p. 270-298, Jul. 1989.

LAVOIE, M. Introduction to post-Keynesian economics. Basingstoke: Palgrave Macmillan, 2006.

LAWSON, T. The nature of heterodox economics. Cambridge Journal of Economics, v. 30, n. 4, p. 483-505, 2006.

LUCAS, Robert. Studies in business-cycle theory. Cambridge: The MIT Press, 1981.

LEIBENSTEIN, H. Bandwagon, Snob, and Veblen effects in the theory of consumers demand. The Quarterly Journal of Economics, v. 64, n. 2, p. 183-207, 1950.

MAYHEW, A. The beginning of the institutionalism. Journal of Economic Issues, v. XXXI, n. 3, p. 971-997, 1987.

MAYHEW, A. Contrasting origins of the two institutionalisms: the social science context. Review of Political Economy, v. 1, n. 3, p. 319-333, Jul. 1989.

MAYHEW A. All consumption is conspicuous. In: FULLBROOK, E. Intersubjectivity in economics: agents and structures. London and New York: Routledge, 2002, p. 43-55.

MASON R. The social significance of consumption: James Duesenberry's contribution to consumer theory. Journal of Economic Issues, v. 34, n. 3, p. 553-572, 2000.

MASON, R. Conspicuous consumption in economic theory and thought. In: FULLBROOK, E. Intersubjectivity in economics: agents and structures. London and New York: Routledge, 2002, p. 85-104. 
A interpretação marginalista do consumo conspícuo: inconsistências e limitações da síntese neoclássica da ...

MCCORMICK K. Duesenberry and Veblen: the demonstration effect revisited. Journal of Economic Issues, v. 17, n. 4, p. 1125-1129, 1983.

MINSKY, H. John Maynard Keynes. London: The McMillan Press Ltd., 1975.

MINSKY, H. Stabilizing an unstable economy. New York: McGraw Hill, 1986.

MOAV, O.; NEEMAN, Z. Saving rates and poverty: the role of conspicuous consumption and human capital. The Economic Journal, v. 122, n. 563, p. 933-956, 2012.

MODIGLIANI, F. Liquidity preference and the theory of interest and money. Econometrica, v. 12, n. 1, p. 45-88, Jan. 1944.

MONASTERIO, L. M. Guia para Veblen. Pelotas: Edufpel, 1998, 153p.

PASINETTI, L. Growth and income distribution: essays in economics. Cambridge: Cambridge University Press, 1974.

PATINKIN, D. Money, interest, and prices: an integration of monetary and value theory. New York: Harper \& Row Publishers, 1965.

PATSIOURAS, G.; FITCHETT, J. A. The evolution of conspicuous consumption. Journal of Historical Research in Marketing, v. 4, n. 1, p. 154-176, 2012.

POSSAS, M. L. Um modelo dinâmico multissetorial. Pesquisa e Planejamento Econômico, v. 14, n. 2, p. 477-524, ago. 1984.

POSSAS, M. L. A cheia do "mainstream": comentário sobre os rumos da ciência econômica. Revista de Economia Contemporânea, n. 1, p. 13-58, jan./jun. 1997.

RAE J. [1834]. The sociological theory of capital: being a complete reprint of new principles of political economics. New York: The MacMillan Company, 1905.

RUTHERFORD, M. What is wrong with the new institutional economics (and what is still wrong with the old)? Review of Political Economy, v. 1, n. 3, p. 299-318, 1989.

SALLES, A. O. T.; CAMATTA, R. B. O utilitarismo de Jevons e a crítica de Veblen acerca da teoria do consumo. Revista Economia Ensaios, p. 77-108, jan./jun. 2014.

SALLES, A. O. T.; CAMATTA, R. B. Para além do consumo conspícuo: a teoria do consumo de Thorstein Veblen em A Teoria da Classe Ociosa e em The Theory of Business Enterprise. In: SAlleS, A. O. T.; PESSALI, H. F.; FENÁNDEZ, R. G. Economia institucional: fundamentos teóricos e históricos. São Paulo: Unesp, 2017.

SAMUELS, W. The present state of institutional economics. Cambridge Journal of Economics, v. 19, p. 569-590, 1995.

SAMUELSON, P. [1947]. Fundamentos da análise econômica. São Paulo: Nova Cultural, 1986. (Coleção Os Economistas). 
SILVA, V. L. Da matriz historicista ao holismo metodológico no institucionalismo Vebleniano. Economia e Sociedade, v. 22, n. 2, p. 335-366, 2013.

TOBIN, J. Asset accumulation and economic activity. Chicago: University of Chicago Press, 1980.

TODOROVA, Z. Conspicuous consumption as routine expenditure and its place in the social provisioning process. American Journal of Economic and Sociology, v. 72, n. 5, p. 1183-204, Nov. 2013.

TODOROVA, Z. Consumption as a social process. Journal of Economic Issues, v. XLVIII, n. 3, p. 663-678, Sept. 2014.

TOPOROWSKI, J. Michat Kalecki: an intellectual biography. Volume I: Rendezvous in Cambridge 1899-1939. Hampshire: Palgrave Macmillan, 2013.

TRIGG, A. B. Veblen, Boudieu and conspicuous consumption. Journal of Economic Issues, v. XXV, n. 1, p. 99-115, 2001.

VEBLEN, T. B. The economic theory of woman's dress. Popular Science Monthly, v. 46, n. 2, p. 198-205, Dec. 1894.

VEBLEN, T. B. [1898a]. Por que a economia não é uma ciência evolucionária? In: SALLES, A. O. T.; PESSALI, H. F.; FERNÁNDEZ, R. G. Economia Institucional: fundamentos teóricos e históricos. São Paulo: Unesp, 2017, p. 31-52.

VEBLEN, T. B. The instinct of workmanship and the irksomeness of labor. American Journal of Sociology, v. 4, n. 2, p. 187-201, 1898 b.

VEBLEN, T. B. [1899]. A teoria da classe ociosa: um estudo econômico das instituições. São Paulo: Abril Cultural, 1983.

VEBLEN, T. B. The preconceptions of economic science. The Quarterly Journal of Economics, v. 14, n. 2, p. 240-246, Feb. 1900.

VEBLEN, T. B. [1904]. The theory of business enterprise. New York: Cosimo, 2005.

VEBLEN, T. B. [1915]. Imperial Germany and The Industrial Revolution. Kitchener: Batoche Books, 2003.

VEBLEN, T. B. The instinct of workmanship and the state of the industrial arts. New York: The MacMillan Co., 1918.

VEBLEN, T. The place of science in modern civilization and other essays. New York: B. W. Huebsch, 1919.

VERCELLI, A. Methodological foundations of macroeconomics: Keynes and Lucas. Cambridge: Cambridge University Press, 1991. 
A interpretação marginalista do consumo conspícuo: inconsistências e limitações da síntese neoclássica da ...

WEBER, C. M. The thinning of Veblen's "Conspicuous Consumption" in the modern language of economics. (Working Paper, 2011). Disponível em: http://cameroneconomics.com/cc.pdf.

WEINTRAUB, S. Keynes, Keynesians, and monetarists. Pennsylvania: University of Pennsylvania Press, 1978.

WOODSIDE, A. G. Economic psychology and fashion marketing theory appraising Veblen's theory of conspicuous consumption. Journal of Global Fashion Marketing, v. 3, n. 2, p. 55-60, 2012. 